\title{
Correlation, price discovery and co-movement of asset-backed securities and equity ${ }^{1}$
}

\author{
Andreas A. Jobst ${ }^{2}$ \\ International Monetary Fund (IMF), International Capital Markets Department (ICM), \\ 700 19th Street, NW, Washington, DC 20431, USA; e- mail: ajobst@imf.org
}

Received: 21st December, 2005

Andreas A. Jobst is an economist at the International Capital Markets Department (ICM) of the International Monetary Fund (IMF) in Washington, D. C. His research focuses on structured finance, (credit) risk management, sovereign debt management, financial regulation and time series econometrics. He previously worked at the Federal Deposit Insurance Corporation (FDIC), the Deutsche Bundesbank, the Financial Market Group (FMG) in London, the Center for Financial Studies (CFS) in Frankfurt/Main, the European Central Bank $(E C B)$, the Bank of England, the U.N. Economic Commission for Latin America and the Caribbean (ECLAC), Deutsche Bank and the Boston Consulting Group (BCG). He holds a PhD in Finance from the London School of Economics (LSE). He was also educated in Oxford, Cambridge, Leicester and Maryland.

\section{Practical applications}

On the heels of prominent and headline-grabbing downgrades and defaults of several U.S. corporates in 2005, subsequent haircut unwinding of CDO and CDS positions exposed to these corporates did not only resuscitate regulatory concerns about risk measurement standards, but also raised groundswell concern about the knock-on effects of shocks in derivative markets on other investment classes. In this regard, the paper explores one possible inter-linkage based on a reduced form simultaneous equation model of the joint price dynamics of publicly traded equity and default sensitive asset-backed securities (ABS) issued by the same entity. Estimation results suggest a consistent long term intertemporal association between both asset classes, which ascribes information benefits to ABS as a leading indicator of price discovery. The negative correlation of investment-grade ABS and equity provides an attractive long-term hedging possibility at times when declining ABS spreads would allow equity holders to cover their asset position in anticipation of falling share prices. These findings are particular useful for finance executives of corporations seeking alternative ways of diversified funding, institutional investors, hedge fund managers and investment banks in the structured finance market as well as service providers, such as risk consultants and prime brokers.

\begin{abstract}
Asset-backed securitisation has become a viable and increasingly attractive risk management and refinancing method either as a stand-alone form of
\end{abstract}

structured finance or as securitised debt in collateralised debt obligations (CDO). The absence of industry standardisation, however, has prevented rising investment demand from Vol. 12 No. 1/2, 2006, pp. 60-101

(c) Palgrave Macmillan Ltd Ltd $1747-4426 / 06 \$ 30.00$ 
translating into market liquidity comparable with traditional fixed income instruments, in all but a few selected market segments. In particular, low financial transparency and complex security designs inhibit profound analysis of secondary market pricing and how it relates to established forms of external finance. This paper represents the first attempt to measure the intertemporal, bivariate causal relationship between matched price series of equity and ABS issued by the same entity. In a two-dimensional linear system of simultaneous equations, it investigates the short-term dynamics and long-term consistency of daily secondary market data from the UK sterling asset-backed securities (ABS)/mortgage backed securities (MBS) market and exchange traded shares between 1998 and 2004 with and without the presence of cointegration. The causality framework delivers compelling empirical support for a strong co-movement between matched price series of ABS-equity pairs, where ABS markets seem to contribute more to price discovery over the long run. Controlling for cointegration, risk-free interest and average market risk of corporate debt hardly alters the results. Once the magnitude and direction of price discovery on various security characteristics, such as the ABS asset class, are qualified, however, it is found that ABS-equity pairs with large-scale commercial MBS/residential $M B S$ and credit card/student loan ABS reveal stronger lead-lag relationships and joint price dynamics than whole business ABS.

\section{INTRODUCTION}

\section{Research question}

In integrated and efficient capital markets, financial assets with similar risk characteristics should yield similar expected returns, so investors expect to earn similar risk-adjusted returns on comparable exposures. Similarly, a consistent and close pairwise association is also observed between market prices of different state-contingent claims when their value depends on the same underlying asset-generating process, such as the empirical relationship between bonds and stocks. The emergence of alternative off-balance-sheet (structured) finance begs the question of whether asset-backed securities (ABS) also share a similar pattern of intertemporal association with the market value of the issuing firm. This paper examines whether price co-movement does exist between publicly traded equity and default sensitive ABS issued by the same entity - and, if so, whether lower agency cost of asymmetric information of securitised debt improves price discovery. Past research on the empirical relationship of issued claims and securities on similar exposures has been limited to traditional on-balance-sheet asset classes.

The investigation of the empirical relationship between ABS and equity of the same issuer has topical appeal. The substitution of market-based external finance for credit finance through asset securitisation has developed into an increasingly attractive risk management and refinancing method. The emergence of new forms of external finance has only recently prompted a more thorough investigation into the asset correlation and possible causal interaction between different asset claims on similar exposure, such as cash markets (eg corporate bonds) and structured finance/derivative markets (eg credit default 
swaps (CDS)). In a three-dimensional autoregressive specification of bond, equity and CDS prices of the same issuer, Norden and Weber ${ }^{3}$ corroborate previous studies ${ }^{4}$ that find that CDS and equity prices are cointegrated over the long run and share a stationarity difference series under the assumption of no arbitrage. ${ }^{5}$ Earlier studies ${ }^{6,7}$ specifically explore the credit risk pricing between the bond and CDS markets and find little price discrepancy if swap rates are chosen as benchmark risk-free rates. Empirical evidence on the lead-lag relationship in capital markets suggests primary price discovery in the CDS market $^{8}$ (especially in capital market-based financial systems and liquid CDS markets on large firms) and price adjustment in bond and equity markets. So far, however, no research study has attempted to account for price dynamics of $\mathrm{ABS}$ and equity markets for loss of available and suitable market data.

Asset-backed securities tranches provide opportunities of active arbitrage through both put-call-parity replication of equity and can be structured to match the asset correlation of other conventional investments and indices. Nonetheless, the primary and secondary markets of ABS still exhibit certain shortcomings: (i) the notoriously complex security design of multi-layered synthetic transactions and the lack of rigorous standardisation ${ }^{9}$ impairs fair asset pricing and restricts informed investment; (ii) the dominance of a few players (mainly banks, institutional investors and other money managers) is a deterrent to the lending width in the market; (iii) investors prevent market deepening by holding ABS deals until maturity ('buy and hold'); (iv) the absence of comprehensive trading platforms inhibits efficient information dissemination across different segments of capital markets; and (v) low retail participation impedes greater diversification of ABS demand across the financial system. All these features dull the efficiency of price discovery in ABS markets and largely compromise the adequate specification of price dynamics. ${ }^{10}$

This paper investigates the intertemporal, bivariate causal relationship between matched equity and ABS prices of the same issuer. In efficient financial markets, one would expect state contingent financial claims with different risk exposure but identical (or very similar) underlying fundamental assets to share a cointegration relationship with a difference stationarity (base) series. In keeping with technically related work on price co-movement in CDS and bond markets, vector autoregression methods with and without cointegration restriction (vector autoregression (VAR) and vector error correction model (VECM)) are adopted to support a comprehensive (non-structural) causality test framework of random disturbances on a linear, two-dimensional system of simultaneous autoregressive equations of time-varying means.

Traditional (linear) Granger causality testing is also employed to investigate the presence of the linear predictive power of past price movements in pairwise issuer-matched price series in both markets. The short-term dynamics and long-term consistency of co-movement between matched ABS and equity prices are defined as jointly 
determined by the lagged polynomials of past observations and individual price adjustments of each asset class after controlling for risk-free interest and the market price of risk. In particular, the efficiency of price discovery in response to changes in the quality of issuers and their securitised debt is studied. The approach improves short-term univariate forecasts of price movements in each market and reveals whether the asset correlation and the joint dynamics associated with the causal interaction of cointegrated price movements significantly inform the price formation in each market over time. The methodology is applied to a dataset of actual market prices covering a pool of 68 matched pairs of UK ABS and equity price series over a time period of more than five years. Although the degree and direction of price discovery on various security characteristics of selected ABS, such as issue (credit) quality, maturity and securitised asset class (whole business ABS vs commercial MBS/residential MBS/other ABS) is qualified, the lack of fundamental information about the credit-linkage of securitised assets to the operational performance of the issuer does not permit fully efficient pricing of ABS and equity under equivalence conditions within integrated capital markets. Nonetheless, the methodology yields stylised facts about price discovery in both markets over time, which might guide future theoretical and empirical research into potential divergence in price discovery between different capital market sectors.

Several new issues emerge from the research. Only weak empirical support is found for the argument that the joint dynamics of $\mathrm{ABS}$ and equity prices improve univariate, short-run predictions of future price movements. Notwithstanding this result, the lead-lag relationship of ABS and equity prices over the long run is statistically and economically meaningful, with ABS markets dominating price discovery. If one tests for cross-sectional sensitivity of error correction, one finds that that the strength of long-term intertemporal causality and the relative importance of $\mathrm{ABS}$ markets seem to vary substantially by rating, maturity and asset type of ABS issue. ${ }^{11}$ The VAR-based specification of co-movement between ABS and equity pairs indicates that the contribution of ABS markets to price discovery is substantially stronger for CMBS/RMBS/other ABS than for whole business ABS. Despite the robustness of the findings to the order of cointegration, cross-sectional variation in the intertemporal relationship between ABS and equity prices warrants more empirical and theoretical research.

This paper is structured as follows. The properties of the dataset and the technical specifications of various causality tests are presented. The proposed methodology is reviewed and the time series properties of the sample are linked to previous findings in the literature. After a thorough discussion of the results, the paper concludes with a summary of significant findings and recommendations for possible extensions, improvements and further research.

\section{Research motivation}

On the heels of Standard \& Poor's downgrading of General Motors and Ford 
Figure 1: Overview of risk transfer instruments.

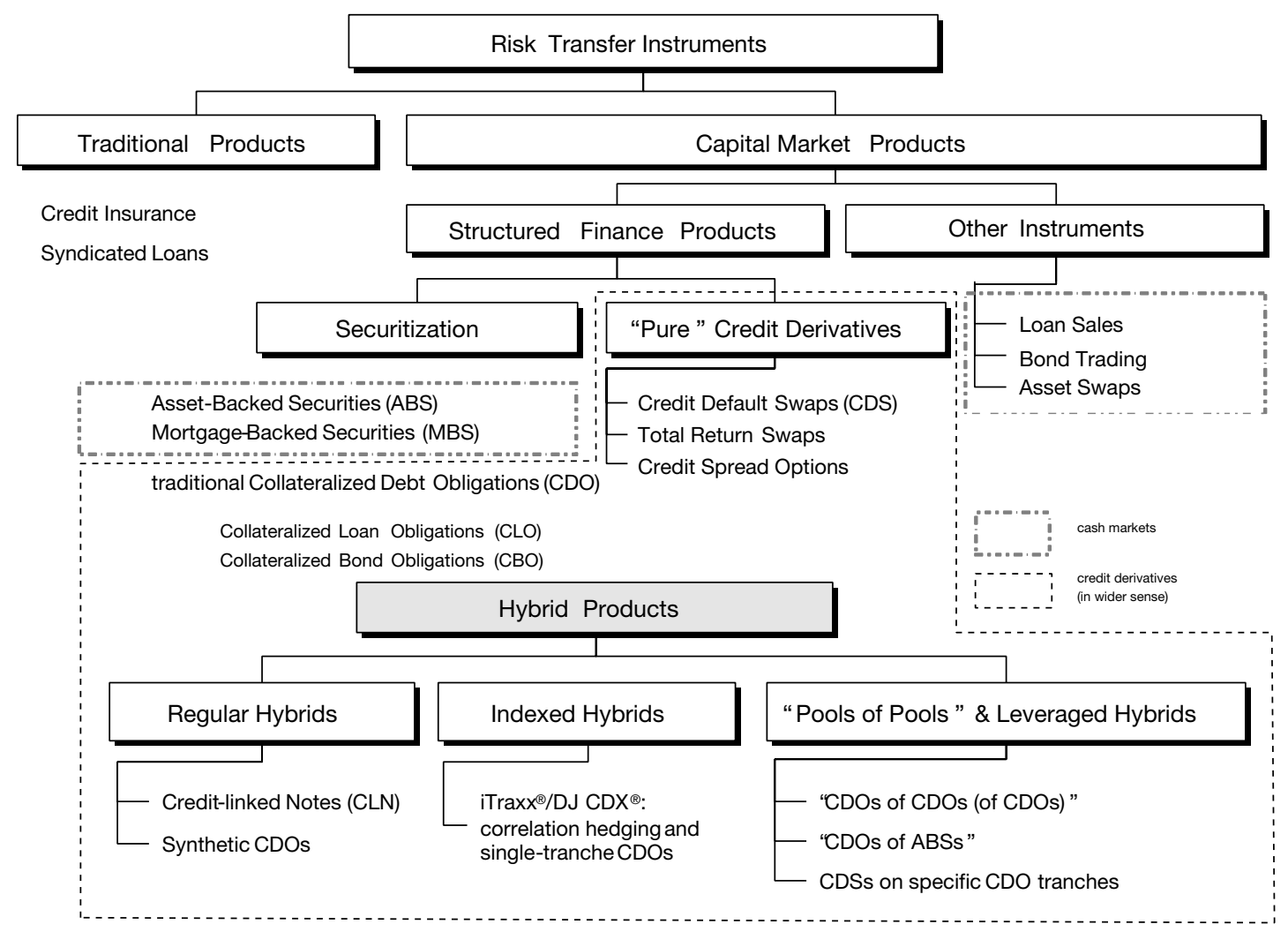

Source: adapted from Jobst, A. (2005) 'What is Structured Finance ?', 30th September, SSRN Working Paper, and Effenberger, D. (2003) 'Frankfurt Voice: Credit Derivatives Implications for Credit Markets', Deutsche Bank Research

Motor Co. to non-investment grade status in April 2005, a drumbeat of warnings was issued about the soundness of the economic reasoning and risk measurement standards of collateralised debt obligations (CDOs). Subsequent haircut unwinding of CDO positions exposed to these corporate downgrades raised groundswell concern about the knock-on effects of the CDO market on other investment classes. The recent high-profile bankruptcies of automotive supplier Delphi as well as Northwest and Delta airlines in the US in November 2005 now has investors and regulators worrying about the resilience of these leveraged structured claims to potentially risky corporate debt as reference assets in times of stress. This recent unfolding of events has been anticipated by several scholars in the field of asset pricing CDOs, ${ }^{12}$ which looks for potential trouble spots in this segment of fixed income 
markets. Over the last few years, the CDO market has been the fastest growing area of structured finance. Generally, a CDO represents a form of asset-backed securitisation, which converts large pools of mostly illiquid exposures into commoditised structured claims issued as tradable capital market debt instruments. The conventional security design of CDOs with tranche subordination as a risk-sharing mechanism induces a leverage effect on constituent tranches, whose distinct risk-return profiles can be tailored to specific investment preferences. ${ }^{13}$ Synthetic CDOs are classified as 'hybrid' risk transfer instruments and credit derivatives in a wider sense (see Figure 1). In contrast to cash CDOs, they enlist wads of credit derivatives to create partially funded and highly leverage investment from synthetic claims on the performance of designated credit exposures. ${ }^{14}$ Whereas the classification 'pure credit derivatives' only applies to CDSs, total return swaps and credit spread options - unfunded/partially funded structured finance transactions - synthetic CDOs straddle the indistinct boundary between securitisation and credit derivatives. The synthetic assembly of credit exposures and the composition of derivative elements in complex, subordinated CDO transactions pose interesting questions about the valuation and price formation of leveraged credit risk transfer mechanisms in structured finance.

The flexible structure of synthetic CDOs allows issuers to devise an almost infinite number of ways of combining various asset classes in order both to transfer asset risk by shortening the notional amount of designated asset exposures and to arbitrage 'spreads between different debt markets, between debt of different issuers, between different classes of debt on a single company's balance sheet ${ }^{\prime 15}$ or between comparable securities on similar fundamental asset values. Actually, the unfunded combination of distinct contingent claims is essential to turning asset correlation of selected securities into a tradable asset class, which can be leveraged depending on the seniority of investment. This property of CDOs had led to the emergence of growing interest in asset correlation and price dynamics between different investment products in the bid to detect and exploit pricing anomalies of credit risk. In addition to CDSs, many CDO structures also include seasoned ABS deals in 'pools of pools' reference portfolios ('CDOs of ABSs' or 'CDO' ${ }^{2}$ ). ${ }^{16}$ Hence, the asset correlation and the joint price dynamics of ABS prices and other traded security prices are fundamental to the development of robust forecasting models for dynamic portfolio adjustment and the risk management of synthetically composed credit exposures and their dynamic adjustment over time.

Since ABS can be issued as a stand-alone asset class or included in a more evolved combination of structured claims, the price dynamics of ABS as senior debt claims on the securitised exposures also involve important aspects of corporate finance and capital structure choice. Reference assets underlying ABS transactions are typically 'fenced out' from the total asset value of the issuer. Depending on the transaction 
Figure 2: Pay-off profile of equity and bond prices before and after securitisation according to OPT

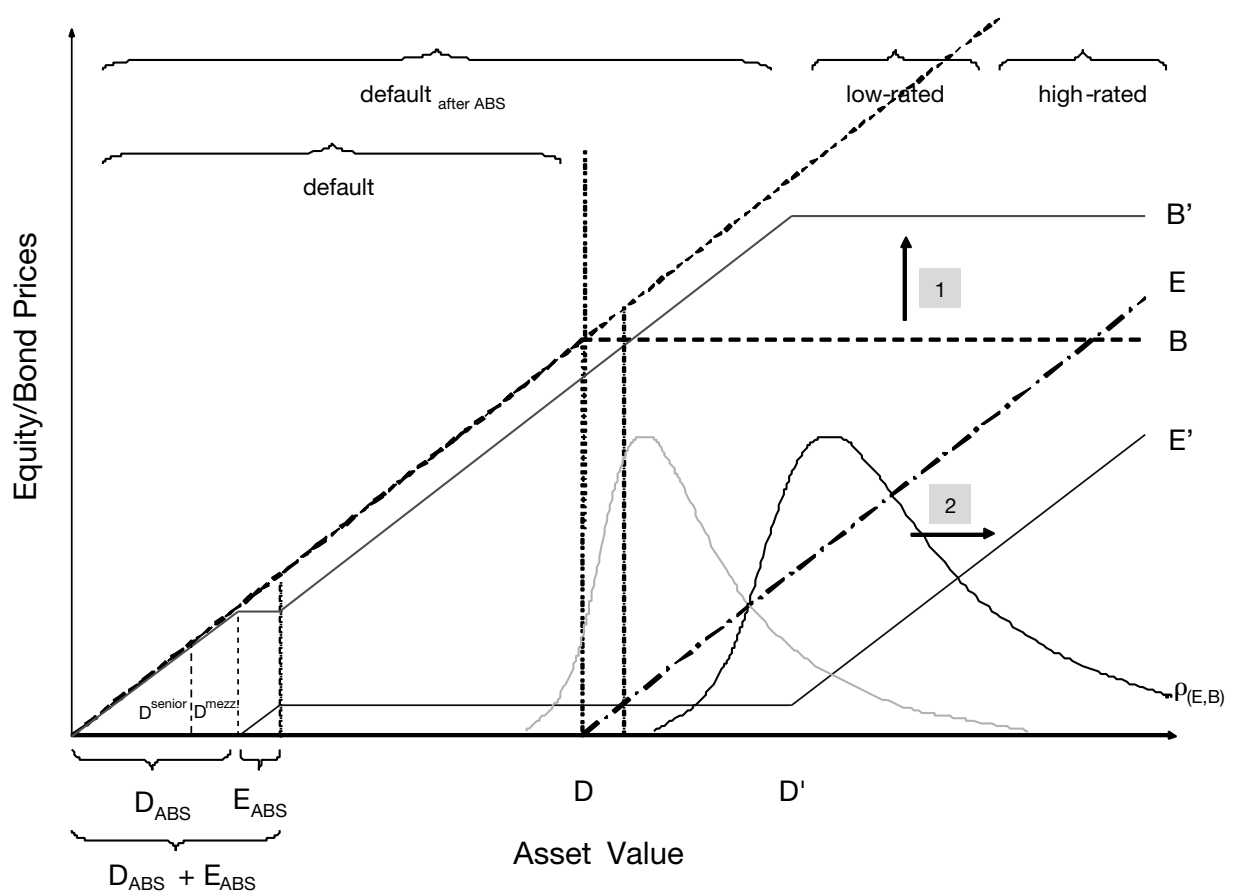

structure of various types of ABS (true sale vs synthetic), securitised claims can preserve a very close economic and legal association with the issuer's asset value changes.

Moreover, many issuers of ABS retain an equity claim as a highly leveraged call option on the residual value of securitised exposures, which constitutes a reservation utility upon maturity if realised losses fall short of expected losses. The linkage of ABS reference assets to the asset performance of the issuer, determines the strength of the empirical relationship between $\mathrm{ABS}$ and equity claims. It also indicates whether the option-pricing theory (OPT)-based correlation of debt and equity valuation $^{17}$ applies to the market prices of
ABS tranches and equity issued by one and the same entity.

Relationship between bond prices, ABS prices and equity

In synthetic $\mathrm{CDO}$ and $\mathrm{ABS}$ transactions with on-balance-sheet reference assets, the intuition behind the empirical relation of securitised debt and equity claims can be assessed within the theoretical valuation of balance sheet identities in the context of the capital structure-based OPT. ${ }^{17,18}$ According to Merton's structural model, owners of corporate equity in leveraged firms have the option to default if their firm's asset value (reference asset) declines below the cumulative face value of 
outstanding debt (strike price). So, corporate bond investors effectively write European put options to equity owners, who hold a residual claim on the firm's asset value (see Appendix 1). The factors that determine the riskiness of debt are the duration, the leverage of the firm and the asset value volatility. Hence, equity and debt are always positively correlated. Their correlation increases in higher default risk and leverage, which imply a higher probability that the asset value of the firm will drop below the default threshold. Bond and equity prices should also be cointegrated and share an equilibrium price relationship.

Figure 2 illustrates the stylised profile of equity and bond prices of a leveraged firm with a notional amount of outstanding debt ('default threshold') D. The firm is in default if its asset value falls below the notional amount of outstanding debt. The correlation between bonds and equity declines asymptotically to zero. By keeping the debt level constant, if the firm is low-rated and operates at a high risk of default, the chances of both equity holders and creditors being affected by bankruptcy are high, so one would expect a high correlation between bonds and equity (see Figure 2) as one traverses levels of asset value that warrant a low credit rating. At a sufficiently high firm asset value, the distance to default reaches a level, at which the chances of bankruptcy become remote and the correlation between bonds and equity tapers off.

The different state-contingent pay-off functions of equity and debt claims on firm value in the traditional capital structure choice of on-balance-sheet funding cause agency costs of asymmetric information. Debt represents a disciplinary device to prevent non-value maximising managers from implicitly transferring wealth from creditors to equity holders ('asset substitution') if low levels of debt allowed them to engage in risky investments with sub-optimal (risk-neutral) return. ${ }^{19}$ An excessive debt burden, however, induces the opportunity cost of abandoning profitable future investment opportunities ('underinvestment problem ${ }^{20}$ ). Asset securitisation might redress these conflicts of interest between creditors and shareholders, ${ }^{21}$ because it allows issuers to appropriate partial debt holder wealth by carving out a defined pool of reference assets to satisfy securitised debt claims, which capture ex ante gains from the firm's future asset value. Thereby, issuers subordinate existing creditors and render existing debt less inhibitive on the realisation of new investment opportunities. ${ }^{22}$ The bankruptcy level increases to $D^{\prime}$ (even if the reference assets are sold off-balance, which would shrink the total asset base of the issuing firm). The illustration also shows that the issuance of ABS discounts the future asset value of securitised exposures, whose pay-offs would have otherwise accrued to equity holders if the firm did not default at maturity. The correlation between bond and equity prices should still persist and be consistent over time, though at different statistical significance and higher asset values of the firm, if the issuing firm retains appreciable default risk after the ABS transaction. 
Also note that positive correlation due to the issuer's proximity to bankruptcy coincides with the notion of securitisation as a preferred form of external finance if issuers face high capital costs of internal funds according to the pecking-order ${ }^{23}$ and debt trade-off theories of capital structure choice under asymmetric information. ${ }^{24}$ In keeping with the pecking-order theory, ${ }^{25}$ lower agency cost from valuation uncertainty renders securitised debt safer than straight debt, as the value of the insulated reference portfolio can be assessed more precisely than the issuer's firm value. ${ }^{26}$ Since capital market investors in securitisation transactions receive their payment directly from a diversified pool of asset exposures insulated from the issuer, securitised debt carries lower agency cost. Hence, debt holders of ABS would require less information about the issuing firm than debt holders of (unsecured) corporate bonds or equity holders to make an equally informed assessment about the fundamental asset value. Therefore, the analysis of the intertemporal relation between ABS and equity prices is tantamount to gauging the joint price dynamics of asset classes with different degrees of informed investment for a certain capital structure decision.

\section{Sensitivity of securitised debt to the issuer's asset value}

Asset-backed securities do not reflect the present value of any gains from the firm's future investment income outside the reference portfolio. The credit risk associated with their estimated future repayment, however, is indicative of the issuer's asset quality. Almost all securitisation transactions maintain a significant degree of economic and/or legal association with the original issuer. In contrast, equity claims derive their value as a call option on current and future operational gains from overall issuer performance above some bankruptcy threshold. Given these characteristics, the strength of the price relationship between equity and $\mathrm{ABS}$ issues is expected to depend on the security design of ABS. In the case of synthetic structures, for instance, the issuer retains credit-linkage to securitised exposures, which exposes the issue to the counterparty risk emanating from the volatility of the issuing firm's value over time. ${ }^{27}$ In the alternative case of a true sale transaction with a complete legal transfer of selected asset exposures, it is commonplace to observe first loss coverage by issuers as a structural support mechanism to mitigate the agency costs of asymmetric information. Here, the market price of ABS is contingent on whether the asset value of the issuing firm implies adequate financial capacity to support first loss coverage. ${ }^{28}$ The upshot is that one expects the strength of the intertemporal relationship of ABS to the distribution of the issuing firm's value to depend on the linkage of securitised debt to issuer performance.

\section{Hypotheses}

The capital structure-based correlation of debt and equity as well as the sensitivity of securitised exposures to the asset value of the issuing entity establish a sound theoretical foundation to the joint price dynamics of securitised debt and equity. Great importance is ascribed to both the 
economic linkage of securitised exposures to the future performance of the issuer and asset correlation of ABS and equity claims as possible constituent elements of synthetic CDOs. These insights are applied to a comprehensive analysis of the joint price dynamics of name-matched ABS and equity pairs to gain a better understanding of information processing in ABS markets vis-á-vis equity markets in response to changes in the fundamental asset value of issuers. The research motivation delivers three complementary hypotheses, which substantiate the economic plausibility of an intertemporal causal relation between equity and ABS prices.

Hypothesis 1: If one rules out any ABS transaction that would increase the issuer's liabilities beyond its asset value, securitised debt is positively correlated with equity of the same issuer, and both share a long-term equilibrium price relationship. Since structural models ascribe higher call option value to equity the higher the duration of outstanding debt, the firm leverage and the volatility of firm assets, low-rated issuers and/or issuers that operate close to bankruptcy exhibit a stronger degree of correlation than highly rated issuers.

Hypothesis 2: The type of ABS defines the proximity of ABS debt to the asset value process of the issuer. The closer the economic and/or legal association between securitised exposures and the issuer (eg project finance, whole business securitisation), the more sensitive securitised debt will be to changes in the fundamental asset value of the issuer.
In this case, economically strong and statistically meaningful long-term consistency is found between price movements of equity and securitised debt.

Hypothesis 3: ABS markets are expected to lead equity markets in price discovery of the fair market value of firm performance. Outside investors can assess the fair value of ABS more easily than the value of other forms of external finance, mainly because securitised debt is specifically issued on the back of designated exposures.

Hypothesis 4: Given Hypotheses 2 and 3, ABS transactions with a close economic and/or legal association with the asset value of the issuer better inform the price formation of corresponding equity than do other types of ABS, such as CMBS and RMBS issues.

\section{DATASET}

Although ABS has established itself as an increasingly attractive structured finance mechanism for investors looking for greater diversification and lower risk exposure than with traditional corporate bonds, rising investment demand has yet failed to translate into a level of market liquidity comparable with conventional fixed income markets. Hence, reliable trading data of securitised debt as a truthful reflection of market price volatility is hard to come by. For this analysis, access was granted to a proprietary database of market prices collected by a major European commercial bank as a syndicated member of the iBoxx bond index. More than five years' worth of 
daily $^{29}$ secondary market (indicative) bid quotes of fixed-interest tranches of UK sterling-denominated ABS ('sterling ABS/MBS'), one of the most actively traded ABS asset class in Europe (see Figure 1), were obtained. ${ }^{30}$ These ABS price series were reconciled with the price information of exchange-traded equity issued by the same exchange-listed entities (see Figure 2). The UK bond benchmark with a 15-year weighted average maturity was also collected from Bloomberg and the three-month $\mathrm{LIBOR}^{31}$ on UK sterling deposits from Thomson Financial Datastream. The initial ABS panel dataset covered the daily quoted security (bid) prices (250 working days p.a.) of a maximum of 1,405 observations from 1st September, 1998, to 24th January, 2004, of 149 individual tranches of 104 UK sterling denominated ABS and MBS transactions. The author was able to obtain specific ABS security information, such as issuer name, tranche specification (class of note), issue date, original rating, principal value, coupon rate (fixed), maturity date, domicile of securitised assets, type of ABS transactions (whole business ABS, captive finance ABS, CMBS, RMBS (prime), multi-borrower ABS, equipment leasing ABS, credit card ABS, student loan ABS), denomination of securitised assets and ISIN. ${ }^{32}$ The time series of observed price quotes was complete in all but a few instances. Missing observations of daily price information were substituted by linear interpolation. ${ }^{7}$ Four defaulted or matured tranches were eliminated from the database, leaving a total of 145 ABS tranches of 78 transactions.

Subsequently, the availability of shares prices of as many issuers of ABS transactions as possible was verified to create matched ABS-equity pairs. A combined query of various sources, including Reuters, Bloomberg, Thomson Financial Datastream, Yahoo Finance and The Financial Times Online, generated only 36 issuers (or parent companies of issuers in the case of consolidated subsidiaries and/or lines of business) of the ABS dataset, which were publicly listed at the London Stock Exchange or at other exchanges (in the case of foreign parent companies of UK-domiciled issuers). ${ }^{33}$ The author was able to assign equity price series (end-of-day mid-quotes) to a corresponding set of 81 ABS tranches of 42 ABS transactions. ${ }^{34}$ Out of all 81 ABS tranches issued by exchange-traded entities (or their parent company), 55 were classified as whole business ABS, project finance (captive finance) ABS or other ABS (eg credit cards and student loans), whereas the remaining 26 tranches were either CMBS or RMBS. Another set of 11 ABS series (from five individual transactions), which shared only a small time window of price observations with the matched equity series, rendering it useless for co-movement analysis, was finally excluded. After elimination of two further ABS-equity pairs owing to level persistence in order to avoid biased estimation results, the final data sample consisted of 68 matched ABS-equity pairs (with 31 different issuers of 38 ABS transactions).

Asset-backed securities transactions in matched ABS-equity pairs were distinguished by ABS properties (type of ABS asset class, rating category and 
maturity) to analyse the cross-sectional sensitivity of the estimation results.

Asset-backed securities-equity pairs with different ABS asset classes might exhibit different price co-movement due to a higher degree of association of equity and ABS prices in the case of whole business and captive finance ABS ('whole business ABS') as opposed to RMBS, CMBS and other ABS (student loans, credit cards, equipment leasing, multi-borrower) transactions ('CMBS/RMBS/other ABS'), ${ }^{35}$ which are mostly issued by financial institutions or large parent/holding companies. It is conjectured that the market pricing of the latter type of ABS might be less sensitive to equity price changes; yet, higher market liquidity and greater transparency of CMBS/RMBS could also engender stronger joint price dynamics.

The rating classification of each ABS tranche was recorded and a composite rating a consensus view of an initial issue rating was formed in cases when two or even three rating agencies have assigned tranche ratings (see Appendix 2, Table A1) to identify the overall rating. Most tranches are rated by all three rating agencies (30), with 41, 44 and 64 tranches being rated by Moody's, S\&P and Fitch, respectively. Only 11 tranches are rated by just one rating agency. If tranches are rated by at least two rating agencies, they are more likely to have been rated by Fitch and either S\&P or Moody's. A lower incidence of joint ratings by Moody's and S\&P conforms to the notion that many issuers of ABS elect either of the two divergent rating approaches by Moody's or S\&P as primary rating agency to obtain the most favourable rating. The Fitch rating could be thought of as a third-party 'seal of approval'. The mean and median composite ratings of all $A B S$ tranches in the total sample are 4.16 ('AA-'/'Aa3') and 3.00 (AA, $\mathrm{Aa} 2)$ on the numeric rating scale, with the highest rating classification 1.00 ('AAA'/'Aaa') being most common. ${ }^{36}$

\section{METHODOLOGY}

In order to test for the existence of a price equilibrium, the methodology follows a sequence of analytical procedures commensurate with the incidence of possible cointegration relations in the joint dynamics of $K$ number of price series. If $k=K$, the time series of all variables in the sample are level stationarity, and the use of an unrestricted VAR specification of price dynamics without a cointegration vector is warranted. If $1 \leq k-1 \leq K$, one series is first-order differentiable so that at least one cointegration vector (ie difference stationarity) exists. This case requires a cointegration restriction of VAR in the form of a VECM specification or a Granger causality test procedure if the individual series are also level stationarity. ${ }^{37}$ Finally, if $k=0$, all series are at least first-order integrated. In this case, one would calculate VAR estimates on first difference of price series data.

Since inference procedures of standard parametric models assume non-integration and level stationarity of both dependent and explanatory variables, each time series is analysed for individual stationarity at level and first differences by means of unit root tests. Based on a linear price relationship of stationarity series, the traditional Granger test 
of any linear predictive power in the (short-term) price dynamics of pairwise matched equity and ABS prices for each issuer is completed. The stationarity requirement is relaxed in favour of long-term economic causality through cointegration. The presence of cointegration in the long-term relationship between equity and ABS price series is examined in order to control for possible biased inference procedures in a linear specification of higher-order integrated pairwise time series.

The concept of cointegration is defined as the stationarity linear combination of two time series, ${ }^{38}$ whose long-run equilibrium relationship converges to a difference stationarity series, ie the values of the linear combination of the coefficients of the cointegration vector are centred around a mean and have a constant variance. ${ }^{39}$ So if the constituent price series are first-order integrated and share a cointegration relationship, the equivalence relationship between both markets on an equilibrium price holds and their difference series describes a stationarity process. In other words, as the stationarity condition of individual series is dropped, the existence of cointegration allows one to test for a long-term empirical price relationship and empirical causality of short-term price adjustments. A vector-based simultaneous equation model of autoregressive specification is adopted to study the intertemporal causal interaction of both markets with and without the presence of long-term cointegration. VAR and VECM are used as appropriate econometric tools for measuring the speed and the degree of price discovery in these markets.

\section{STATIONARITY AND COINTEGRATION}

Prior to the examination of the lead-lag relationship between equity and ABS prices in a causality framework of several simultaneous equation models, one needs to examine the univariate stochastic properties of the price series in the sample. The price series could either exhibit mean reversion or conform to a random walk with a constant forecast value, conditional on time and time-varying autocovariance, whose first-order integration yields a stationarity difference series. Classical Augmented Dickey-Fuller (ADF) and Phillips-Perron $(\mathrm{PP})^{40}$ unit root test statistics are chosen to investigate the presence of mean reversion. These tests are based on a linear $\operatorname{AR}(p)$ model with $p$ number of lags, which considers all combinations of price sensitivity ? to past mean prices and the significance of some resilient price level as drift. The ADF test is run with a linear trend on level and first differences of spreads of up to five lags in order to control for serial correlation. The PP test diagnostic is also completed, corrected by the Newey-West ${ }^{41}$ autocorrelation consistent variance estimator, ${ }^{42}$ which accounts for the number of periods of serial correlation through six truncation lags. For both tests, Davidson-MacKinnon ${ }^{43}$ critical values are employed for (one-sided) rejection of the unit root null hypothesis. The analysis is complemented by testing for statistically significant residual autoregressive effects on the basis of the Ljung-Box Q-statistic. ${ }^{44}$ In contrast to the most recent study on secondary market pricing in ABS/MBS markets, ${ }^{45}$ it is found that the asset-generating processes of both ABS and 
equity series are generally difference stationarity. The sample mean and median values of the ADF and PP test statistics as well as high degrees of autocorrelation suggest that ABS price series especially defy level stationarity. Similar to earlier research on the price dynamics of US ABS/MBS spreads, both ADF and PP test diagnostics strongly reject the null hypothesis of a unit root in all cases for ABS and equity prices at first difference. This implies stationarity residual series with autocorrelation effects of up to five lags at most according to the Ljung-Box Q-statistic. Since first-order integration of individual equity and ABS price series yields stationarity $\mathrm{I}(0)$ processes, the unit root test estimates suggest that equity and $\mathrm{ABS}$ prices share at least one unique co-integration vector, where a mean-reverting difference series with time-independent autocovariance suggests an intertemporal relationship of mutual price discovery.

Market liquidity and data frequency are identified as possible causes of slightly divergent stochastic properties across equity and ABS prices at level and first differences. Although the sample period stretches more than five years (from September 1998 to January 2004), varying lengths of price quote series for the various $A B S$ transactions result in median (mean) of 698 (683) observations over the sample period — about half the 1,404 (1,539) observations obtained for the equity price of the corresponding issuers in question. Moreover, only weak and scarce statistical evidence is found of mean-reverting ABS prices. Whereas Koutmos ${ }^{45}$ used weekly time series data of more than 30 years to substantiate his findings on the level stationarity of US MBS spreads (grouped by rating classification and maturity), the shorter time horizon certainly inhibits the same degree of measurability of long-range cycles of mean-reversion, even though one is almost always able to match the absolute number of observations in his study. It is also recognised that persistent stochastic processes over long spans of time with a small autoregressive component (due to low liquidity and infrequent trading activity) could bias the ADF and PP tests into rejecting the unit root in the absence of strong statistical power against the alternative of level stationary. ${ }^{46}$ Although 'stale' price movements with autoregressive residuals are not observed, this might well be the case for the comparatively short time horizon of five years. It is found that first-order integration yields strong mean reversion, which in turn renders standard hypothesis testing appropriate for either ABS or equity prices at first differences with and without cointegration.

In an effort to explain the long-term consistency of joint movements of equity and ABS prices, the time series data for the degree of pairwise correlation with and without cointegration restriction (see Appendix 2, Tables A2 and A3) and the existence of one or more cointegration vectors (see Appendix 2, Table A4) were also tested. For the entire sample of ABS-equity pairs, it is found that a (median) positive correlation is most prevalent in the sub-sample of ABS-equity pairs with either non-investment grade rated ABS or whole business ABS. This observation concurs with the structural 
model-based hypotheses of higher correlation between debt and equity of low-rated issuers and issuers of ABS transactions that imply a higher degree of proximity to the fundamental asset value process of the issuer, such as whole business ABS. The joint incidence of both characteristics, however, yields a negative correlation value. This result is attributed to the uneven sample composition by cross-sectional characteristics of ABS-equity pairs. Conditioning the analysis on cointegrated ABS-equity pairs strengthens overall average pairwise correlation and all correlation estimates for the sub-sample control group of whole business ABS, while leaving sub-samples with CMBS and other ABS largely unaffected.

Since both $\mathrm{ABS}$ and equity price series reflect the market value of different security claims on the same asset-generating process (albeit at different degrees of exposure and state contingency), one would expect their difference series to be first-order integrated with a time-invariant mean and autocovariance. The existence of a cointegrating relationship is defined as $B_{i, t}=\alpha_{i}+\beta_{i} S_{i, t}$ with $\alpha_{i}=0$ and $\beta_{i}=1$ for each $i$ pair of ABS and equity series with prices $B_{t}$ and $S_{t}$. If the cointegration restriction is removed from the difference stationarity series, long-term consistency of price co-movement toward an equilibrium price would yield the one-dimensional cointegration vector $k \times 1$, with vector $[1,-1]$ representing the simplest form of first-order cointegration. Johansen ${ }^{47}$ as well as Hansen and Joselius ${ }^{48}$ are followed to examine the existence of statistically significant cointegration on the basis of the trace statistic. ${ }^{49}$ Supporting evidence is found for at least one statistically significant cointegration vector at a 95 per cent confidence level in 51 out of 68 cases of the total sample of matched ABS-equity pairs. Moreover, long-run price consistency between matched equity and ABS series appears to vary by ABS asset class, with the long-term price dynamics of whole business ABS diluting the economic and statistical significance of cointegration. While almost 80 per cent of all ABS series of CMBS/RMBS are cointegrated with the corresponding equity price of their issuer at a statistical significance of 5 per cent or lower, a similar degree of cointegration is observed only in 70 per cent of all ABS series of whole business ABS.

\section{SHORT-TERM DYNAMIC LINKAGES AND LONG-TERM CONSISTENCY}

The investigation of a possible empirical relationship between ABS and equity prices is broken down into short-term dynamic linkages and long-term consistency of intertemporal co-movement. The short-term dynamics between equity and ABS prices is first examined without the requirement of cointegration in two different linear specifications of stationarity series. Before a two-dimensional VAR model in a linear system of simultaneous equations is applied to studying price discovery in response to changes in the quality of issuers and their securitised debt, the traditional linear approach of Granger causality testing is resorted to in order to explain current and future price movements in $\mathrm{ABS}$ and equity markets better on the 
basis of short-term joint (multivariate) price dynamics.

\section{Granger causality}

The Granger causality test ${ }^{50}$ is a non-vector forecasting alternative to VAR (see below) and yields insights about the direction of the empirical relationship between equity and ABS prices, without imposing limitations on the long-run consistency of price dynamics. Granger defines the causality between two scalar-valued, stationarity and ergodic time series $\left\{X_{t}\right\}$ and $\left\{Y_{t}\right\}$ on the grounds of significant reciprocal (autoregressive) influence of past information on the conditional probability distribution of $X_{t}$. Given the bivariate information set $I_{t-1}$, defined as $L x$-length lagged vector $X_{t-L x}^{L x} \equiv\left(X_{t-L x}, X_{t-L x+1}\right.$, $\left.\ldots, X_{t-1}\right)$ of $X_{t}$ (or, in short, a lag polynomial $I_{t-1}\left(L_{x}\right)$ of $\left.X_{t}\right)$ and an $L y$-length lagged vector $Y_{t-L Y}^{L \gamma} \equiv\left(Y_{t-L x}, Y_{t-L x+1}, \ldots, Y_{t-1}\right)$ of $Y_{t}$, the time series $\left\{Y_{t}\right\}$ strictly Granger causes $\left\{X_{t}\right\}$ if one can reject $F\left(X_{t} \mid I_{t-1}\right)=F\left(X_{t} \mid I_{t-1}-Y_{t-L \gamma}^{L \gamma}\right)$ for time period $t$. So past knowledge about past values of $\left\{Y_{t}\right\}$ helps predict current and future values in $\left\{X_{t}\right\}$. The bivariate autoregressive specification of Granger causality with intercept reads as

$$
\begin{aligned}
\Delta S_{t}= & c_{1}+\sum_{j=1}^{q} \alpha_{1, j} \Delta B_{t-j}+\sum_{j=1}^{q} \beta_{1, j} \Delta S_{t-j} \\
& +\xi_{1,1} L_{t}+\xi_{1,2} M_{t}+\boldsymbol{v}_{1, t} \\
\Delta B_{t}= & c_{2}+\sum_{j=1}^{q} \alpha_{2, j} \Delta B_{t-j}+\sum_{j=1}^{q} \beta_{2, j} \Delta S_{t-j} \\
& +\xi_{2,1} L_{t}+\xi_{2,2} M_{t}+\boldsymbol{v}_{2, t}
\end{aligned}
$$

where the non-autoregressive disturbance terms $v_{1, t}$ arn $v_{2, t}$ are i.i.d. and follow a zero mean process with constant variance $N\left(0, \sigma^{2}\right)$. This specification of intertemporal causality of non-cointegrated, difference stationarity series tests whether the coefficients of the lagged polynomials of first-order equity and $A B S$ prices, $\Delta S_{t}=S_{t}-S_{t-1}$ and $\Delta B_{t}=B_{t}-B_{t-1}$, are jointly zero on the basis of standard F-tests. Also included is the three-month LIBOR rate $L_{t}$ and a 15-year UK bond market benchmark rate $M_{t}$ as weakly level stationary, explanatory variables. The lag length $q$ is chosen using the Akaike information criterion (AIC), the Bayesian information criterion (BIC) and the Schwarz information criterion (SIC). A maximum lag of six days is selected. The joint rejection of $H_{0}: \beta_{1, t-1}=\beta_{1, t-j}=\ldots=$ $\beta_{1, t-q}=0$ implies that $\Delta S_{t}$ strictly Granger causes $\Delta B_{t}$. Similar statistical significance of $\alpha_{2, t-j}$ across all lagged endogenous variables indicates a similar feedback effect of $\Delta B_{t}$ on $\Delta S_{t}$. Bi-directional feedback as two-way Granger causality exists if both lagged polynomials of the opposite asset class are sufficiently significantly different from zero so that the exclusion restriction is rejected.

The Granger causality specification of short-term joint price dynamics indicates statistical significance of lagged polynomials of either ABS or equity prices (as past information sets) in roughly 40 per cent of all selected ABS-equity pairs of the total sample and sub-samples (see Appendix 2, Tables A4 and A5). The richness of the dataset allows Granger causality to be estimated at different levels of statistical significance and across cross-sectional variations of ABS characteristics of both ABS categories, CMBS/RMBS and whole 
business ABS, within the total sample of ABS-equity pairs. In the total sample, the null hypothesis of no Granger causality of ABS prices (at first difference) on equity prices (25.0 per cent of all ABS-equity pairs) is rejected more frequently than Granger causality of equity prices (14.7 per cent of all ABS-equity pairs). Past ABS prices are generally at least twice as likely as past equity prices to Granger cause price movements of equity once the selection of eligible price series data is narrowed to cointegrated ABS-equity pairs and further ABS properties, such as UK domiciled issuers, investment grade rating and long-term maturity. When the total sample is broken down into sub-samples of ABS-equity pairs with either CMBS/RMBS or whole business ABS, an intriguing variation in the explanatory power of lagged polynomials of equity and ABS series is detected. In the subset of ABS-equity pairs with whole business ABS, price changes of equity series tilt the general pattern of joint short-term price dynamics of $\mathrm{ABS}$ and equity series against pervasive ABS-based Granger causality. Now, past equity prices (at first difference) chip away considerably at the dominant ABS discovery and claim higher explanatory power in price discovery almost (or even more than) three times as often as past ABS prices. In contrast, the sub-sample of ABS-equity pairs with CMBS/RMBS mirrors the general pattern of Granger causality estimates observed for the price series data of all ABS-equity pairs (ie the total sample of cointegrated series). Here, ABS series outscore equity price series in price discovery at a rate of four to one. Despite the weak stochastic reliability of Granger causality compared with subsequent estimations based on two-dimensional vector-based estimations, one can make a coherent case for strong price discovery by ABS (equity) prices in ABS-equity pairs with CMBS/RMBS (whole business ABS) at first difference invariant of the presence of cointegration concerning short-term co-movements with ABS and equity prices. The findings suggest that the joint price dynamics of both asset classes are superior to univariate forecasts of future price changes of either asset class (at least over the short run). The low importance of past information of whole business ABS prices in the price formation of equity seems to suggest that whole business ABS series might display lower autoregressive effects at higher levels of persistence than corresponding equity series of the same issuer compared with CMBS/RMBS series. One needs to be mindful, however, of the change in sample composition as two ABS asset-class specific sub-samples (whole business ABS vs CMBS/RMBS) of different sizes (31 cases vs 38 cases) are derived. Although the (linear) Granger causality framework testifies to a consistent pattern of a lead-lag relationship between equity and ABS price series, it does not provide conclusive evidence about actual economic causality, even if one controls for non-linearity bias. Hence, the investigation is advanced to a vector-based system of simultaneous equations.

\section{(Unrestricted) vector autoregression}

As a vector-based alternative to Granger causality testing of short-term dynamics, a two-dimensional VAR is presented to analyse the dynamic impact of random disturbances on interrelated time series. 
The linear equation system of VAR assumes stationarity of exogenous and endogenous variables without restricting the interrelated time series to a cointegrating relationship. Since most ABS and equity prices in the sample series are not $\mathrm{I}(0)$ level stationary, the (unrestricted) VAR of vector $\left.X_{t}=\Delta S_{t}, \Delta B_{t}\right)^{\prime}$ of equity and ABS prices at first differences at time $t$ is specified as ${ }^{51}$

$$
\begin{aligned}
{\left[\begin{array}{l}
\Delta S_{t} \\
\Delta B_{t}
\end{array}\right]=} & {\left[\begin{array}{l}
c_{1} \\
c_{2}
\end{array}\right]+\left[\begin{array}{l}
\sum_{j=1}^{p} \varphi_{1, j} \Delta B_{t-j} \\
\sum_{j=1}^{p} \varphi_{2, j} \Delta B_{t-j}
\end{array}\right] } \\
& +\left[\begin{array}{l}
\sum_{j=1}^{p} \gamma_{1, j} \Delta S_{t-j} \\
\sum_{j=1}^{p} \gamma_{2, j} \Delta S_{t-j}
\end{array}\right]+\left[\begin{array}{l}
\xi_{1,1} L_{t} \\
\xi_{2,1} L_{t}
\end{array}\right] \\
& +\left[\begin{array}{l}
\xi_{1,2} M_{t} \\
\xi_{2,2} M_{t}
\end{array}\right]+\left[\begin{array}{l}
\varepsilon_{1, t} \\
\varepsilon_{2, t}
\end{array}\right]
\end{aligned}
$$

with $C$ as a $(2 \times 1)$ vector of constants $c_{1}$ and $c_{2}, \phi_{t}$ as $(2 \times 2)$ parameter coefficient matrix for past $X_{t}$ values up to $p$ number of lags, ${ }^{52} \Xi_{t}$ as $(2 \times 2)$ parameter coefficient matrix of vector $Z_{t}=\left(L_{t}, M_{t}\right)^{\prime}$ of the contemporaneous level controls $L_{t}$ (three-month LIBOR rate) and $M_{t}$ (bond market benchmark rate) for the risk-free interest rate and average UK corporate bond returns, and $E_{t}$ as $(2 \times 1)$ vector $\left(\boldsymbol{\varepsilon}_{t}^{(\Delta S t)}, \boldsymbol{\varepsilon}_{t}^{(\Delta B t)}\right)^{\prime}$ of non-autoregressive i.i.d. residuals $\varepsilon_{t} \sim N(0, \Sigma) .{ }^{53}$ A lag structure without gaps at a maximal autoregressive lag of order six is considered to capture the weekly variation of the underlying economic relationship for daily observations. The parameter coefficients are estimated as matrix vectors of lagged and contemporaneous values of the designated endogenous variables for each ABS-equity pair across the sample selection.

\section{Vector autoregressive error correction model}

Since most ABS-equity pairs exhibit intertemporal (linear) causality with at least one cointegration vector, intertemporal price adjustment of cointegrated ABS-equity pairs is controlled for to improve the analysis of joint dynamics of past price movements in both equity and ABS markets. The intertemporal lead-lag relationship of price discovery indicates which market is more efficient in reflecting changes in the quality of the issuer (and the value of associated securitised debt). The (unrestricted) VAR specification above is augmented by introducing a so-called error correction term to account for price adjustment of I(1) cointegrated levels of lagged difference series of equity and ABS prices for $B_{i, t}=\alpha_{i}+\beta_{i} S_{i, t}$, where $\alpha_{i}$ and $\beta_{i}$ are endogenously determined. A two-dimensional (bivariate) VECM is applied as a restricted VAR ${ }^{54}$ to time series data of ABS-equity pairs that are known to be cointegrated. This specification allows one to extend the perspective to the long-term consistency of price dynamics and lays the foundation for a more advanced investigation into the economic causality of prices in both markets. A CM restricts the long-run behaviour of endogenous variables to converge to their cointegrating relationships (through price adjustments), while allowing a wide range of short-run dynamics of past price movements as random disturbances on joint price dynamics within a linear system of simultaneous equations. The degree of cointegration is reflected in the specification of the error correction term, which gradually corrects past deviations from long-run equilibrium through a series of 
partial short-run price adjustments. Although the cointegration restriction of long-term consistency in VECM does not necessarily require level stationary of the constituent time series, it implies a level stationary I(0) difference series of each time series, regardless of the individual degree of integration.

A VECM with constant drift and no trend for difference stationarity series of ABS and equity prices at time $t$ with at least one cointegrating vector is considered as

$$
\begin{aligned}
X_{t}= & C+\Lambda\left(B_{t-1}-\alpha_{0}-\beta_{1} S_{t-1}\right) \\
& +\sum_{j=1}^{p} \phi_{t} X_{t-j}+\Xi_{t} Z_{t}+E_{t}
\end{aligned}
$$

where $C, \phi_{t}, X_{t}, \Xi_{t}$ and $Z_{t}$ are identical to the parameter specification of VAR above. The lagged difference between both level series denotes the 'error correction term' (or 'cointegration equation') as an additional endogenous variable of possible long-term consistency (with complete cointegration at $\alpha_{0}=0$ and $\left.\beta_{1}=1\right) . \Lambda$ is a $(2 \times 1)$ vector of adjustment coefficients $\lambda_{1}$ ('equity $\lambda$ ') and $\lambda_{2}$ ('ABS $\lambda$ ') of the (contemporaneous) error correction term. The adjustment coefficients indicate the degree of short-term price adjustment by movements of equity prices vis-á-vis ABS prices and vice versa, so as to correct pricing discrepancies against a long-term trend of difference (covariance) stationarity. If $\lambda_{1}$ is sufficiently positive in the above specification of error correction, ABS prices anticipate price changes (eg due to changes in the quality of securitised assets) and the mean-reverting parameter of equity prices adjusts to remove pricing errors in response to changes of issuer valuation (eg due to changes in credit conditions). The converse argument holds, and equity prices contribute most to price discovery relative to ABS prices if $\lambda_{2}$ is sufficiently negative. The (relative) degree of adjustment to price discrepancies is reflected in the economic significance of coefficient $\beta_{1}$, so the statistical and economic significance of the error correction term indicates which of the two markets lags price changes, and how fast price adjustment takes place. If (significant) positive values for $\lambda_{1}$ and negative values for $\lambda_{2}$ coincide in the $\lambda$-vector of the error correction term, the relative magnitude of both $\lambda_{1}$ and $\lambda_{2}$ coefficients reflects the role of each market in price discovery (see Appendix 2, Table A7).

Besides analysing the incidence of statistical and economic significance of error correction in the ABS and equity equation of VECM individually, the pattern of joint price adjustment of cointegration for each matched ABS-equity pair in the sample is also examined. Hence, as a succinct representation of the lead-lag relationship between both series, different ratios of the respective error correction coefficients are computed to gauge how much each market contributes to price discovery. Two indicative measures of relative error correction are entertained: the (original) Gonzalo and Granger ${ }^{55}$ (GG)-test measure $\lambda_{1} /\left(\lambda_{1}-\lambda_{2}\right)$ and a modified version $\left(\lambda_{1}-\lambda_{2}\right) /\left(\left|\lambda_{1}\right|+\left|\lambda_{2}\right|\right)$ ('modified GG test') thereof, where $\lambda_{1}$ and $\lambda_{2}$ denote the error correction term coefficients for equity and ABS prices, respectively. Both ratio tests complement each other to provide instant information about the dominant contribution to price discovery and the corresponding adjustment for pricing errors in either 
market. The GG-test measure emphasises the relative magnitude of error correction terms in both the $\mathrm{ABS}$ and equity equation of VECM, but it does not explicitly check for the signs of the $\lambda$ coefficient values. In contrast, the modified GG-test measure resembles a sign test of the 'right' combination of error correction coefficients for dominant price discovery of a lead-lag relationship. If the GG-test approaches unity, the 'equity $\lambda$ ' dominates, implying that the price series of the first term in the error correction term $\left(B_{t-1}-\alpha_{0}-\beta_{1} S_{t-1}\right)$ of VECM plays a leading role in price discovery and the second term adjusts. If the ratio is close to 0 , the roles of these two markets reverse. For a measure close to 0.5, both markets equally contribute to price discovery, and there is no definite evidence of consistent price adjustment in either series over time. Positive values of the modified GG-test attribute greater economic significance to price adjustment of the second term of the error correction equation, whereas the reverse holds true for negative values of the modified GG test (see Appendix 2, Tables A8 and A9). If ABS prices adjust with certainty, one finds $G G_{\text {mod }}=-1: \lambda_{1}<>\lambda_{2} \forall \lambda_{1}<0, \lambda_{2}>0$ and, in the opposite case of 'pure' price discovery by equity prices, one finds $G G_{\text {mod }}=-1: \lambda_{1}<>\lambda_{2} \forall \lambda_{1}<0, \lambda_{2}>0$ (see Figure 3).

\section{ESTIMATION RESULTS}

Both the unrestricted and restricted two-dimensional vector-based estimation of intertemporal autoregressive effects between equity and ABS prices within a linear system of simultaneous equations in VAR and VECM show that lagged prices of each asset class have similar statistically significant explanatory power to improve forecasts on the short-term joint price dynamics with and without cointegration. In a nutshell, the findings generally conform to Hypothesis 1 of a positive long-term consistency of intertemporal causal interaction (co-movement) between cointegrated equity and ABS prices, where the ABS market contributes more to price discovery of issuer valuation (Hypothesis 3), albeit with some variations across different sub-samples of ABS security characteristics. Although whole business ABS display an economically stronger empirical association with corresponding equity prices (Hypothesis 2), the incidence and statistical significance of price discovery is stronger for CMBS/RMBS/other ABS (with lower sensitivity to changes in equity value). Hence, Hypothesis 4 is rejected.

\section{Lagged polynomials in VAR and VECM}

The utility of this exercise lies in the comparative investigation of the statistical and economic significance of short-term joint dynamics of pairwise matched equity and $\mathrm{ABS}$ price series based on the coefficient estimates of lagged polynomials in VAR and VECM specifications. The degree to which past information in both markets improves univariate estimates of autoregressive effects is investigated.

A detailed analysis of the incidence of VAR and VECM estimated coefficients of the lagged polynomials at a common level of at least 10 per cent statistical significance testifies to a largely positive and statistically 
Figure 3: Long-term consistency of price dynamics: VECM-based estimation of the error correction term ('equity $\lambda^{\prime},\left(1\right.$ and 'ABS $\lambda$ ', $\lambda_{2}$ ) of all cointegrated $A B S$ and equity prices over the entire sample of matched $A B S$-equity pairs. The alpha-numerical sector preference (1-8) is geared towards statistically and economically significant price discovery by the ABS market. Observations of error correction coefficients in sectors $B$ and $C$ indicate 'pure plays' of dominant price discovery by $A B S$ and equity price information respectively. The statistical importance of error correction on the basis of 'significance categories' 1-3 is also distinguished, which indicates that both ABS and equity show statistically significant error correction (3), only the equity series shows statistically significant error correction (2) or only the ABS series shows statistically significant error correction (1)

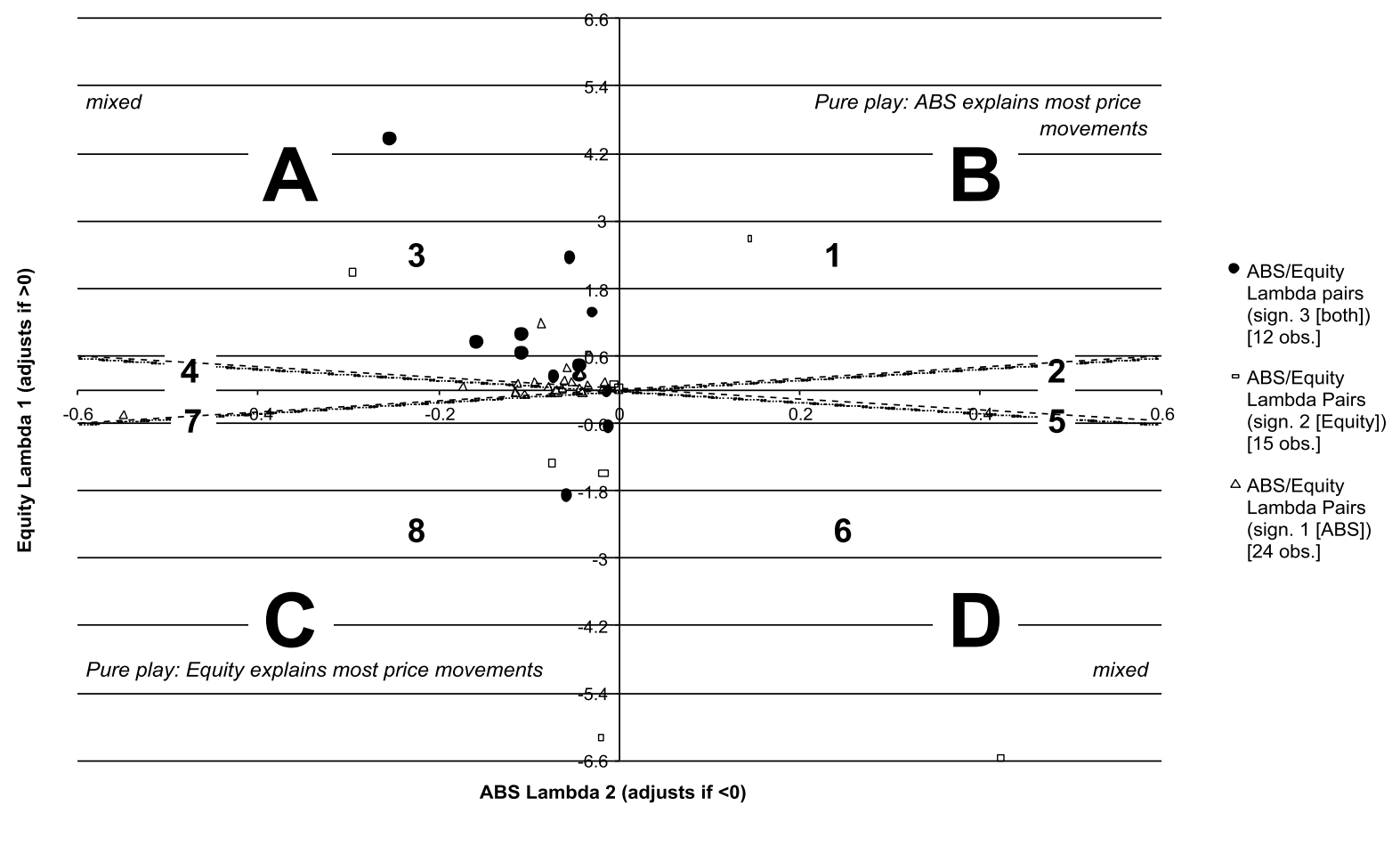

significant influence of past joint price dynamics of ABS-equity pairs on short-run forecasts of current and future price movements (Hypothesis 1), with greater overall economic significance attributable to price information of ABS-equity pairs with whole business ABS (Hypothesis 2) and ABS with long maturities. While the lagged polynomials of ABS exhibit consistently negative autoregressive effects in both VAR and VECM, mostly negative (positive) autoregressive effects in equity prices series up to six lags of past price information are detected in VAR (VECM) specifications. It is found that controlling for cointegration can affect how past knowledge helps 
improve forecasted price movements (results not reported). Strong and statistically significant autoregressive effects in equity price series up to six lags of past price information are detected in both VAR and VECM specifications. ${ }^{56}$ Autoregressive effects of ABS series tend to be similar to equity only with cointegration restriction in VECM. The lagged polynomial of ABS prices (level and first differences) explains changes in equity prices only in the subsets of ABS-equity pairs with (i) CMBS/RMBS in both VAR and VECM (based on a sufficiently high incidence of significant cases), (ii) whole business ABS in VAR (based on a significant FM $t$-statistic), and (iii) ABS with long maturity or investment grade rating (based on a sufficiently high incidence of significant cases). Autoregressive effects of equity on ABS prices are limited to ABS-equity pairs with investment grade rated ABS in both VAR and VECM (based on a significant FM $t$-statistic). The coincidence of significant FM $t$-statistics and a high score of significance cases implies little skewness in the distribution of coefficient values across all series in the sample (which might otherwise bias the statistical significance of parametric testing procedures). The evidence, however, generally negates the statistical significance of short-term joint dynamics between both equity and ABS price series for level data and first differences.

The exogenous control factors, the daily level data of the 15-year UK bond benchmark and the three-month UK sterling LIBOR rate (both obtained from Bloomberg), play an economically strong but statistically weak role in both equity and ABS equations of VECM. It is recognised that the count of significant cases is occasionally inconsistent with the FM $t$-statistic, owing to a skewed distribution of sample coefficient estimates for these control variables. The FM-statistic attributes statistical power to control variables at common levels of significance across various sub-samples only without cointegration restriction (VAR).

\section{Error correction in VECM}

The statistical and economic significance of error correction in the long-run price dynamics of equity-ABS pairs based on the individual incidence of positive or negative coefficients of error correction and the paired coincidence of price adjustment of pooled sample estimates are analysed. The mean and median values of error correction and their individual incidence of the error correction coefficients are summarised, as well as two composite GG-test measures for both the entire sample and pre-defined sub-samples of ABS-equity pairs, where the ABS price series is either a whole business ABS or a RMBS/CMBS transaction. The degree of statistical significance of price adjustment is also controlled for by four designated 'significance categories': (i) both coefficients $\lambda_{1}$ and $\lambda_{2}$ are statistically significant (at least at the 10 per cent level); (ii) only $\lambda 1$ (ie equity price adjustment) is statistically significant (at least at the 10 per cent level); (iii) only $\lambda_{2}$ (ie ABS price adjustment) is statistically significant (at least at the 10 per cent level); and (iv) neither $\lambda_{1}$ nor $\lambda_{2}$ is statistically significant (at least at the 10 per cent level). Moreover, the results of intertemporal causality are 
qualified on the following cross-sectional properties: (i) presence of one or more cointegration vectors between the price series of matched ABS-equity pairs; (ii) issuer domicile of UK sterling denominated ABS/MBS (UK-based issuer vs US and German issuers); (iii) seniority of the ABS transaction (investment grade vs non-investment grade); and (iv) maturity of the ABS transaction (at least 25 years vs shorter maturities).

\section{Analysis of individual error correction coefficients of VECM}

Individual error correction of long-term price consistency in the VECM specification of cointegrated ABS-equity pairs is analysed by means of both sample mean and median of estimated error correction term coefficients $\lambda_{1}$ and $\lambda_{2}$ and numerical incidence of positive and negative values of error correction (see Appendix 2, Table A7). Any cross-sectional variation of the degree of mutual price adjustment across different cases of statistical coincidence of estimated error correction coefficients ('significance categories') and different types of ABS series is examined. It is found that at least one $\lambda$-coefficient in VECM of cointegrated ABS-equity pairs is always statistically significant at the 10 per cent level or better (based on one-sided $p$ values). Although the numerical count of error correction terms reveals sizeable price adjustment in both markets, appreciable differences are found in how much equity and ABS prices contribute to price formation. For all cointegrated ABS-equity pairs (Appendix 2, Table A7, Panel A), ABS prices respond to price discrepancies in 94.1 per cent of all cases, whereas only 60.8 per cent of all equity issues adjust. Equity prices are almost seven times more likely to move ahead in price discovery than the corresponding ABS prices, which lead only in 5.9 per cent of all cases. The degree of error correction and price discovery between equity and ABS prices seems to depend strongly on the type of ABS, but also on the maturity and the rating of ABS. Table A7, Panels B and C imply a preponderance of positive $\lambda_{1}$ values (ie equity prices adjust) with the highest proportional incidence of 64.4 per cent of all cointegrated equity series in the total sample of ABS-equity pairs with UK-based issuers and 66.7 per cent of cointegrated ABS-equity pairs with CMBS/RMBS as ABS asset class. A lower chance of equity-based price discovery in ABS-equity pairs with whole business $\mathrm{ABS}$ as $\mathrm{ABS}$ asset class is also recorded. Also, $\lambda_{2}$ values are highly negative (ie ABS prices adjust) in almost every ABS-equity pair throughout the sample invariant of cointegration and ABS asset properties. The highest incidence of 96.7 per cent for negative $\lambda_{2}$ values for all cointegrated ABS-equity pairs with CMBS/RMBS/other ABS as ABS asset class is marked.

In the light of significant individual intertemporal error correction of both ABS and equity prices, higher economic significance determines the dominant direction of price discovery between these cointegrated series. It is found that equity prices tend to adjust twice as strongly as ABS prices over the same set of matched series (Hypothesis 3) in almost all sample selections. The median sample values of $\lambda_{1}$ 
$\left(\lambda_{2}\right)$ in the total sample of ABS-equity pairs all carry positive (negative) signs, irrespective of the 'significance category' of the matched $\lambda$-coefficients.

It is found that the absolute median (mean) values of error correction are consistently higher for equity prices than for ABS prices at a multiple of up to 3 (44), which implies economic dominance of ABS tranches in price discovery in almost all cases of ABS-equity pairs. Only matched series with equity error correction as the lone statistically significant price adjustment (at 10 per cent level or less) and cointegrated series of ABS-equity pairs with whole business ABS as ABS asset type diverge from the general pattern of absolute dominance of ABS series in price discovery. Negative median sample values of $\lambda_{1}$, however, indicate declining error correction of equity series in response to $\mathrm{ABS}$ price movements. At the same time, corresponding ABS series retain a strong inclination of price adjustment based on highly negative $\lambda_{2}$ values (though statistically insignificant). Once the observations are restricted to price series of ABS-equity pairs with RMBS/CMBS/other ABS, UK-based issuers or ABS tranches with investment grade ratings or long maturity, the results provide strong support for price discovery by the ABS market. It is found to be the most coherent median error adjustment in equity markets whenever whole business ABS prices are disregarded. In fact, the total sample of ABS-equity pairs clouds weak ABS price leadership for ABS-equity pairs with whole business ABS tranches, especially if one takes into consideration the findings from the Granger causality test.

Despite the allegedly closer proximity of whole business ABS transactions to the operational performance of issuers, stronger price discovery by CMBS/RMBS transactions cannot be attributed to longitudinal differences between CMBS/RMBS and whole business transactions, given the positive (negative) correlation of ABS-equity pairs with whole business ABS (CMBS/RMBS). Against the background of CMBS/RMBS price movements leading equity, the strong negative correlation of investment-grade CMBS/RMBS provides a potentially attractive hedging possibility of equity holders. At the same time, several conjectures might plausibly explain the weaker price discovery of whole business ABS (in rejection of Hypothesis 4) on the grounds of liquidity-based market risk and information transparency. Higher liquidity from more frequent trading activity and higher incidence of synthetic transactions structures in CMBS/RMBS deals (with a stronger associated economic linkage to the issuer in the form of payment and insolvency guarantees) could facilitate a closer empirical relationship between ABS and equity price series. ${ }^{57}$ Different market liquidity might also be attributable to concentrated 'buy and hold' ownership by large institutional investors.

The cointegrated relationship between ABS and equity series of the same issuer is marked by more economically profound contribution of ABS markets to price discovery in accordance with Hypothesis 3. Nonetheless, in cases of equity price adjustment as the only significant error 
correction, the results are inconsistent with the general properties of intertemporal causality. In some instances, when disparate autoregressive effects and/or time trends of matched series impede error correction of equity prices, dominant price discovery is also attributed to equity markets. Although this qualification on general price adjustment of equity series seems limited in scale and scope, the findings on the basis of simple non-matched counts of equity error correction do not betray conclusive evidence of pervasive price leadership by ABS markets.

\section{Analysis of paired error correction coefficients of VECM}

Unfortunately, the incidence of statistical significance and the economic significance of individual price adjustment of both ABS and equity series fails to reflect how $\lambda_{1}$ and $\lambda_{2}$ values square up against each other in matched $\lambda$-pairs in the VECM specification of matched ABS-equity pairs. For this purpose, the original and a modified GG-test diagnostic is derived from the coefficient values of the error correction terms of matched ABS and equity series to measure the relative contribution of each market to price discovery (see Appendix 2, Tables A7 and A8). It is found that the values for both GG-tests of matched error correcting $\lambda$ pairs remain largely positive and stable throughout the entire sample and the designated sub-samples of whole business ABS and RMBS/CMBS as well as over most significance categories. Once we limit our analysis to I(1) cointegrated equity-ABS pairs, $\lambda$-pairs with only one significant $\lambda$ value are most common (in two thirds of all cases). Most median values of both GG-tests are close to unity every time paired adjustment coefficients share the same statistical significance (and to a lesser extent when either $\lambda$ value represents the only statistically significant error correction). The GG-test results imply a preponderance of positive $\lambda_{1}$ and negative $\lambda_{2}$, with $\left|\lambda_{1}\right|>\left|\lambda_{2}\right|$, which suggests that ABS investment informs price formation and equity markets almost perfectly adjust to price discovery in the ABS market (Hypothesis 3).

The numerical analysis of paired error correction coefficients at different significance categories is also represented graphically in Figure 3. For 'perfect' price leadership of ABS (equity), one would expect the corresponding $\lambda$ pairs to exhibit statistically significant, positive (negative) $\lambda_{1}$ and $\lambda_{2}$ values, where $\lambda_{2}<\lambda_{1}\left(\left|\lambda_{1}\right|<\left|\lambda_{2}\right|\right)$. The preference order of price adjustment behaviour of ABS and equity price series is represented in segments from 1 (strong evidence of ABS lead in price discovery) to 8 (strong evidence of equity lead in price discovery). Most observations (which incidentally also show the most complete statistical significance of $\lambda$ pairs) are found in segments 3 and 4.

The results of price leadership of ABS are weakest for ABS-equity pairs with whole business $A B S$, irrespective of further cross-sectional variation of ABS characteristics, or whether statistically significant error correction is limited to ABS prices. If only ABS-equity pairs with CMBS/RMBS as ABS series are considered, the GG-tests usually retain positive values across all significance 
categories (except in the case of ABS with long-maturity and/or positive correlation when only the equity series exhibits statistically significant error correction).$^{58}$ For ABS-equity series with whole business ABS, however, matched $\lambda$ pairs yield consistently negative GG-test values whenever the ABS error correction is the only statistically significant price adjustment. Interestingly, the cross-sectional restriction of investment grade and/or long-maturity ABS of eligible ABS-equity pairs marginally improve both the general statistical significance of $\lambda$ pairs and the economic significance of ABS-based price discovery.

\section{CONCLUSION}

In extension of the past literature on the empirical relationship between different asset classes, this paper represents the first attempt to measure the intertemporal causal relationship between matched price series of equity and ABS issued by the same entity. Over a period of more than five years, the short-term dynamic linkages and long-term consistency of price co-movement of selected price series in these markets was investigated, within an autoregressive time series framework of a two-dimensional linear system of simultaneous equations with and without the presence of cointegration. Bivariate VAR and Granger causality testing were applied to paired ABS and equity price series to explain better how their joint dynamics over the short run as well as their intertemporal lead-lag relationship inform current and future prices. The degree and direction of price discovery on various security characteristics of selected ABS were also qualified, such as issue (credit) quality, maturity and the type of ABS transaction (whole business ABS vs CMBS/RMBS/other ABS).

The methodology generated stylised facts about price co-movement, which might guide future research on correlation trading, information dissemination and price formation across different capital market sectors. It was found that knowledge about the joint dynamics of pairwise matched past equity and ABS prices only slightly improved short-term univariate forecasts of price movements of both markets based on a VAR specification. Nonetheless, Granger causality testing and autoregressive specifications of cointegrated price dynamics with correction for intertemporal price adjustment to past innovations revealed that much can be learned about the price formation in each market by analysing the long-term consistency of price movements. Generally, the findings delivered compelling empirical evidence of strong price co-movement (Hypothesis 1) and endorsed pervasive $A B S$ dominance in price discovery between ABS and equity series over time (Hypothesis 3). The results of long-term consistency of price dynamics is economically stronger for cointegrated ABS-equity pairs with whole business ABS (Hypothesis 2). The magnitude and direction of price discovery by ABS markets varies, however, by security characteristics. ABS-equity pairs with large-scale (and investment grade rated) CMBS/RMBS transactions exhibited stronger and statistically more significant lead-lag relationships than did ABS-equity pairs with whole business ABS. In this case, 
ABS prices seemed to contribute little to price discovery over time and were more inclined to adjust to price discrepancies vis-'-vis the matched equity price series (in rejection of Hypothesis 4). This intriguing result was attributed to higher market liquidity and higher incidence of stronger credit-linkage to the issuer in the (mostly) synthetic transaction structures of CMBS/RMBS. ${ }^{59}$

Moreover, the strong negative correlation of investment-grade CMBS/RMBS provides a potentially attractive long-term hedging possibility of equity holders at times when spread compression of securitised debt allows them to cover their asset value in anticipation of declining share price.

This instructive exercise sets the stage for a comprehensive econometric analysis of secondary market price dynamics in ABS markets and the changes of correlation risk in synthetic structured finance transactions - a largely unexplored area of asset pricing. As financial institutions and large corporations administer asset securitisation primarily as a premier asset funding and hedging mechanism, joint price dynamics inform both sound risk management and regulatory policy as regards price discovery and systemic risk between different capital market sectors. Some information benefits can be ascribed to ABS investment, based on the findings about the joint dynamics of $\mathrm{ABS}$ and equity markets within the empirical scope of the analysis.

Many extensions to this paper are feasible, such as nonlinear Granger causality testing by means of a detailed examination of VAR residuals and the cross-validation of squared errors. Additionally, depending on the availability of credit ratings for all equity names in the samples, the examination of the impact of issuer credit ratings on the empirical relationship of debt and equity prices could help in testing Hypothesis 1 more comprehensively. As an econometric improvement, one might need to relax the assumption of non-correlated, zero-mean residuals with unit variance in favour of a transmission mechanism of time-varying innovation through $\mathrm{ARCH}$ effects. Lastly, the most challenging proposition of a subsequent study would be an extension of empirical scope by including highly frequent secondary market data on other ABS markets and/or the inclusion of corresponding bond price information, in keeping with the analysis of the three-way interaction of CDS, equity and bond prices.

\section{References and Notes}

1 FDIC Center for Financial Research Working Paper No. 2005-11.

2 International Monetary Fund (IMF), International Capital Markets Department (ICM), 700 19th Street, NW, Washington, D. C. 20431; Visiting Fellow, Federal Deposit Insurance Corporation (FDIC), Center for Financial Research (CFR), 550 17th Street NW, Washington, DC 20429, USA; E-mail: ajobst@imf.org. The paper represents the views and analysis of the author and does not represent those of the IMF. Any errors and omissions are the sole responsiblity of the author. The paper was completed in large parts during the author's research appointment at the Center for Financial Research (CFR) at the Federal Deposit Insurance Corporation (FDIC). I am indebted to Paul Kupiec for his comments and suggestions.

3 Norden, L. and Weber, M. (2004) 'The Comovement of Credit Default Swap, Bond and Stock Markets: An Empirical Analysis', Center for Financial Studies (CFS), Working Paper No. 2004/20. 
4 Blanco, R., Bennan, S. and Marsh, I. W. (2004) 'An Empirical Analysis of the Dynamic Relationship Between Investment-grade Bonds and Credit Default Swaps', Working Paper, Bank of England (4 March); Zhu, H. (2004) 'An Empirical Comparison of Credit Spreads between the Bond Market and the Credit Default Swap Market', BIS Working Papers No. 160, Bank for International Settlements (August).

5 Chan-Lau and Kim (2004) apply a similar set-up for their analysis of equity prices, CDS prices and bond spreads in emerging markets based on a limited dataset on several sovereigns. Chan-Lau, J. A. and Kim, Y. S. (2004) 'Equity Prices, Credit Default Swaps, and Bond Spreads in Emerging Markets', IMF Working Paper WP/04/27, Washington, DC.

6 Houweling, P. and Vorst, T. (2001) 'An Empirical Comparison of Default Swap Pricing Models', Working Paper, Erasmus University of Rotterdam.

7 Hull, J., Predescu, M. and White, A. (2003) 'The Relationship Between Credit Default Swap Spreads, Bond Yields, and Credit Rating Announcements', Working Paper, J. L. Rotman School of Management, University of Toronto.

8 Note that Norden and Weber as well as Hull et al., ref. 7. above, also find strong evidence that the CDS market anticipates credit rating announcements (particularly negative rating events) of up to three months and more, whereas equity and bond markets register a much short reaction time to changes in credit quality (Norden, L. and Weber, M. (2004) 'Informational Efficiency of Credit Default Swap and Stock Markets: The Impact of Credit Rating Announcements', CEPR Discussion Paper Series No. 4250).

9 Rutledge, A. (2005) 'ABS Analysis - A

Rigorous Approach', The RMA Journal (January), 26-9.

10 Although the Dow Jones iTraxx index of CDS obligations and the iBoxx index of collateralised debt have inaugurated the first round of emerging standardisation, large parts of the ABS market have shed little of their frequently deplored opacity. Market observers point to the changing hedging patterns for customised ABS claims in advent of liquid pricing benchmarks (Tsui, E. (2005) 'Asia poised for take-off in CDOs', Financial Times, Capital Markets, 15th July). For instance, CDOs are generally structured to meet specific investors' needs. In the past, issuers would hedge unbalanced positions through complex subordinated, multi-tranche structures ('transaction-based'), whose complexity inhibited transparent asset pricing. Now, standardised claims on liquid indices (eg Dow Jones iTraxx) offer a base correlation measure ('CDO delta') for the 'market-based' hedging of bespoke and mostly privately transacted single-tranche transactions (arranged for single investors) or multi-tranche transactions with mezzanine tranches indexed to equity prices.

11 The type of ABS could also serve as proxy for degree of insulation of securitised exposures from issuer and the ABS investor's participation in the issuer's future operational performance in many instances.

12 For more theoretical and empirical research on the valuation of CDOs, see Gibson, M. (2004) 'Understanding the Risk of Synthetic CDOs', Working Paper, Division of Research and Statistics, Federal Reserve Board, Washington, DC; Egami, M. and Esteghamat, K. (2003) 'Analysis and Valuation of Subordinate Structures in Collateralized Baskets of Defaultable Obligations', Working Paper, Princeton University; Jobst, A. (2005) 'Tranche Pricing in Subordinated Loan Securitisation', Journal of Structured Finance, Vol. 11, No. 2, pp. 64-96; Jobst, A. (2002) 'The Pricing Puzzle: The Default Term Structure of Collateralised Loan Obligations', Center for Financial Studies (CFS), Working Paper No. 2002/14; Duffie, D. and Gbrleanu, N. (2001) 'Risk and Valuation of Collateralized Debt Obligations', Financial Analysts Journal, Vol. 57, No. 1, pp. 41-59; Duffie, D. and Gârleanu, N. (1999) 'Risk and Valuation of Collateralized Debt Obligations, Unabridged Version', Working Paper, Graduate School of Business Stanford University.

13 Although investors should expect the same returns for CDOs as for similar credit risk exposure in plain vanilla debt, the risk profile of CDO tranches varies dramatically in response to changes in the valuation of the underlying (reference) asset. Jobst, A. (2005) 'Need for Vigilance by CDO Investors', Financial Times, Comments \& Letters, 4th November. Jobst, A. (2005) 'What Is Structured Finance?' (30 September). SSRN Working Paper (http://ssrn.com/abstract=832184, forthcoming in The Securitization Conduit); Jobst, A. (2005) 'Investors Must Heed These CDO Risks', Financial Times, Comments \& Analysis (19 April). 14 Jobst, A. (2003) 'Collateralised Loan Obligations (CLOs): A Primer', The Securitisation Conduit, Vol. 6, No. 1-4. 
15 Shepherd, B. (2005) 'The Synthetic CDO Shell Game', Investment Dealer's Digest, 16th May.

16 'In many instances, investors in CDOs that also include well-diversified ABS deals (alongside individual asset exposures) in their underlying portfolios might unwittingly compromise their diversification at the margin. This is because the pooling of diversified securitised exposures might actually increase the conditional probability of default for systemic risk events and backfire on investors when default correlation increases even slightly’ (Jobst, 2005d).

17 Merton, R. C. (1974) 'On the Pricing of Corporate Debt: the Risk Structure of Interest Rates', Journal of Finance, Vol. 29, pp. 449-470.

18 Although the same intuition applies, the author acknowledges different economic significance, depending on the structural characteristics of ABS.

19 Jensen, M. C. and Meckling, W. H. (1976) 'Theory of the Firm: Managerial Behaviour, Agency Costs and Ownership Structure', Journal of Financial Economics, Vol. 3, pp. 305-360.

20 Myers, S. C. (1977) 'Determinants of Corporate Borrowing', Journal of Financial Economics, Vol. 5, pp. $147-175$.

21 Stulz, R. and Johnson, H. (1985) 'An Analysis of Secured Debt', Journal of Financial Economics, Vol. 14, pp. 501-521.

22 This effect ultimately depends on the way the investment policy guides the riskiness of the use of securitisation proceeds relative to the riskiness of the issuer before the securitisation issue (Jobst, A. (2005) 'Asset Securitisation as a Risk Management and Funding Tool: What Does it Hold in Store for SMEs ?' SSRN Working Paper.).

23 Myers, S. C. and N. S. Majluf (1984) 'Corporate Financing and Investment Decisions When Firms Have Information that Investors Do Not Have', Journal of Financial Economics, Vol. 13, pp. 187-221.

24 The pecking order theory states that firms prefer internal to external finance owing to adverse selection arising from information asymmetry in financial relationships between insiders and outsiders. Without asset securitisation, firms with high internal refinancing cost and low bankruptcy cost generally prefer debt to equity because of lower information costs from valuation uncertainty. In contrast, the trade-off theory postulates that managers choose a leverage level, where the marginal benefit of debt, such as the interest tax shield, just outweighs the costs of debt, including agency and financial distress cost ('optimal trade-off').

25 Additionally, securitised debt does not carry restrictive bond covenants and might be easier to negotiate.

26 Jobst, see ref. 22, above.

27 Depending on the funding level of this type of ABS structure, CDS form an integral part of the security design and contribute largely to a very close association between securitised debt and the issuer valuation, if the issuer retains the role of default protection provider with or without provisions of legal recourse in credit events.

28 The market value of ABS is derived from a pre-defined stream of present or future proceeds ('cash flow ABS', eg 'whole business ABS') or a diversified reference portfolio of existing or future asset exposures, which have been either randomly drawn from a population of own assets ('balance sheet ABS') or acquired for the sole purpose of securitisation ('arbitrage ABS').

29 Similar to Blanco et al. and Zhu, ref. 4, above, in their studies on the leading role of CDS prices in price formation of default risk, the author contests the appropriateness of measuring the short-term dynamic interactions on weekly price observations in Longstaff, F., Mithal, S. and Neis, E. (2003) 'The Credit Default Swap Market: Is Credit Protection Priced Correctly?', Working Paper, UCLA.

30 The data used in the study are not explicitly supported by actual trades and should be viewed as indicative 'matrix' quotes offered by the data provider as bid prices. Hence, the price information might partly reflect an information advantage enjoyed by the data provider as major broker in the sterling ABS/MBS market.

31 The three-month LIBOR is chosen mainly because it is used as base index/reference rate for adjustable rate $\mathrm{ABS}$ tranches in the sterling ABS/MBS market.

32 The International Securities Identifying Number (ISIN) uniquely identifies a fungible security, whose structure is defined in ISO 6166. Securities with ISIN coding can be debt securities, equities, options, derivatives and futures. ISINs consist of two alphabetic characters, which are the ISO 316-1 code for the issuing country, nine numeric digits (the National Securities Identifying Number (NSIN), which identifies the security), and one numeric checksum digit.

33 Equity price series of seven non-UK issuers (Eurohypo AG, W|rttembergische 
Hypothekenbank AG, MBNA America Bank, N.A., SLM (Student Loan Marketing Association) Corp., Allmerica Financial Corporation (AFC), MBNA Bank Corp., Capital One Bank Corp.) were obtained from the New York Stock Exchange (NYSE) and the Frankfurt-based Deutsche Börse (German Stock Exchange). Subsequently, the local currency-denominated stock prices were converted into pounds sterling at the applicable exchange rate.

34 Note that several ABS transactions that were issued by the same entity were retained in the dataset and/or two or more constituent fixed-rate tranches were.

35 This broad distinction of ABS asset classes is adopted in the further analysis of cross-sectional variation of estimation results.

36 The total sample of ABS-equity pairs only includes ABS tranches without past rating events (rating change or rating watch). Failure to do so might otherwise bias the discriminatory analysis of cross-sectional sensitivity of intertemporal error correction in cointegrated series.

37 The linear representation of an equilibrium price relation has proven to be inadequate for non-stationarity time series (Granger, C. W. J. and Newbold, P. (1974) 'Spurious Regressions in Econometrics', Journal of Econometrics, Vol. 2, pp. 111-120). The alternative hypothesis of significant explanatory power in conventional inference procedures (eg ordinary least squares (OLS)) might actually flag an non-existing empirical relation between two variables, which drift away from the initial value with an individually time-varying trend. In this case, the linear Granger causality testing procedure is also biased. Hence, if variables with a unit root are observed, the existence of cointegration is needed to establish incontrovertible evidence of long-term price consistency between time series.

38 Johansen, S. and Juselius, K. (1990) 'Maximum Likelihood Estimation and Inferences on Cointegration - with Applications to the Demand for Money', Oxford Bulletin of Economics and Statistics, Vol. 52, pp. 169-210; Engle, R. and Granger, C. (1987) 'Cointegration and Error Correction: Representation, Estimation and Testing', Econometrica, Vol. 55, pp. 251-276. See also Granger, C. W. J. (1989) 'Forecasting in Business and Economics', 2nd edn, Academic Press, San Diego.

39 So if two series follow a random walk I(1) process and their difference series is stationarity, they are considered cointegrated. The order $d$ of integration $\mathrm{I}(d)$ indicates the number of unit roots contained in a series and the number of differencing operations required to yield a stationarity series. In the context of this paper, the co-integration of two financial series on the same underlying asset process eliminates a long-term arbitrage opportunity by shorting the overvalued asset to finance a long position in the undervalued asset.

40 Dickey, D. A. and Fuller, W. A. (1981) 'Likelihood Ratio Statistics for Autoregressive Time Series with a Unit Root', Econometrica (July), pp. 1057-1072; Dickey, D. A. and Fuller, W. A. (1979) 'Distribution of the Estimators for Autoregressive Time Series with a Unit Root', Journal of the American Statistical Association, Vol. 74, pp. 427-431; Phillips, P. C. B. and Perron, P. (1988) 'Testing for a Unit Root in Time Series Regression', Biometrika, Vol. 75, pp. 335-346.

41 Newey, W. and West, K. D. (1987) 'A Simple, Positive, Heteroskedasticity and Autocorrelation Consistent Covariance Matrix', Econometrica, Vol. 55, pp. 703-705.

42 See also White, H. (1980) 'A

Heteroskedasticity-Consistent Covariance Matrix and a Direct Test of Heteroskedasticity', Econometrica, Vol. 48, pp. 817-838.

43 Davidson, R. and MacKinnon, J. G. (1993) 'Estimation and Inference in Econometrics', Oxford University Press, Oxford.

44 Ljung, G. and Box, G. (1978) 'On a Measure of LAck of Fit in Time Series Models', Biometrika, Vol. 67, pp. 297-303.

45 Koutmos, G. (2002) 'Modelling the Dynamics of MBS Spreads', Journal of Fixed Income, Vol. 12, No. 2, pp. 43-9. See also Koutmos, G. (2001) 'Common Volatility in MBS Returns: A Factor GARCH Approach', Journal of Fixed Income, Vol. 10, No. 4, pp. 59-65.

46 See Papell, D. H. and Prodan, R. (2003) 'The Uncertain Unit Root in US Real GDP: Evidence with Restricted and Unrestricted Structural Change', Working Paper (October), University of Houston. The danger of type II error misspecification, which also operates in the presence of a non-linear data generating process, has critical implications on the interpretation of ADF results for inference testing in the presence of a nonlinear data generating process. The linear specification of ADF biases the unit root test into rejecting the unit root hypothesis (Taylor, A. (2001) 'Potential Pitfalls for the Purchasing-Power-Parity Puzzle ? Sampling and Specification Biases in Mean-Reversion Tests of 
the Law of One Price', Econometrica, Vol. 69, pp. 473-498; Taylor, M. P. and Peel, D. A. (2000)

'Non-linearity Adjustment, Long-run Equilibrium and Exchange Rate Fundamentals', Journal of International Money and Finance, Vol. 19, p. 33-53).

47 Johansen, S. (1988) 'Statistical Analysis of Cointegration Vectors', Journal of Economic Dynamics and Control, Vol. 12, pp. 231-254; Johansen, S. (1991) 'Estimation and Hypothesis Testing of Cointegration Vectors in Gaussian Vector Autoregressive Models', Econometrica, 59, pp. 1551-1580; Johansen, S. (1995)

'Likelihood-based Inference in Cointegrated Vector Autoregressive Models', Oxford University Press, Oxford.

48 Hansen, H. and Joselius, K. (1995) 'Co-integration Analysis of Time Series', RATS (Regression Analysis of Time Series) Econometrics Software.

49 The cointegration rank test by Johansen (Johansen, S. (1991) 'Estimation and Hypothesis Testing of Cointegration Vectors in Gaussian Vector Autoregressive Models', Econometrica, Vol. 59, pp. 1551-1580) investigates the existence of a stationarity linear combination of first-order integrated time series on the basis of a VAR of $\Delta Y_{t}=\Pi Y_{t-1}+\sum_{i=1}^{p-1} \Gamma_{i} \Delta Y_{t-i}+E$ (with difference operator $\Delta)$ as the first difference specification of $Y_{t}=\sum_{t=1}^{p} A_{t} Y_{t-1}+e_{t}$ at an autoregressive lag order $p$ without gaps, with $A_{t}$ and $\Gamma_{i}$ as $(2 \times 2)$ parameter coefficient matrices for the $k \times 1$ price vectors $Y_{t}=\left(S_{t}, B_{t}\right)^{\prime}$ and $\Delta Y_{t}=\left(\Delta S_{t}, \Delta B_{t}\right)^{\prime}$ of past ABS and equity prices, as well as $e_{t}$ and $E_{t}$ as $(2 \times 1)$ vectors $\left(\varepsilon_{t}^{\left(S_{t}\right)}, \varepsilon_{t}^{\left(B_{t}\right)}\right)^{\prime}$ and $\left(\varepsilon_{t}^{\left(\Delta S_{t}\right)}, \varepsilon_{t}^{\left(\Delta B_{t}\right)}\right)^{\prime}$ of serially uncorrelated, zero mean i.i.d. residuals with covariance structures $\Omega$ and $\Sigma$. The Johansen cointegration test evaluates the null hypothesis of no cointegration relation between the selected time series. The author rejects the null hypothesis if the coefficient matrix $\Pi=\alpha \beta^{\prime}$ of $k \times 1$ vectors has reduced rank equal to $1\left(\mathrm{H}_{0}\right.$ : full rank equal to 2), with $\beta$ being the cointegration vector. The existence of cointegrated time series gives rise to an equilibrium price relationship beyond possible linear bias in standard inference models. Its critical values are reported by Osterwald-Lenum, M. (1992) 'A Note with Quantiles of the Asymptotic Distribution of the Maximum Likelihood Cointegration Rank Test Statistics', Oxford Bulletin of Economics and Statistics, Vol. 54, pp. 461-472.

50 Granger, C. W. J. (1969) 'Investigating Causal
Relations by Econometric Models and Cross-spectral Methods', Econometrica, Vol. 37, pp. 424-438.

51 See also Lutkepohl, H. (1991) 'Introduction to Multiple Time Series Analysis', Springer, Berlin, for consistent lag order selection in VAR models.

52 The choice of lag structure and the maximum lag order $p$ reflect a conscious trade-off between over-parameterisation (and the corresponding loss of degrees of freedom) and over-simplification. Since the maximum lag order should capture the overall information processing and aggregation time in each market, individual partial autocorrelation of ABS and equity series in the sample are mainly relied on (Taylor, M. P. and Peel, D. A. (2000) 'Non-linearity Adjustment, Long-run Equilibrium and Exchange Rate Fundamentals', Journal of International Money and Finance, Vol. 19, pp. 33-53) in addition to the AIC and the stepwise maximum likelihood ratio test.

53 Errors are uncorrelated with their own lagged values and all endogenous variables, but may be contemporaneously correlated with each other. The assumption of not serially correlated residuals is not restrictive, since any residual serial correlation could be easily absorbed by an increase in polynomial lag $p$.

54 Hamilton, J. D. (1994) 'Time Series Analysis', Princeton University Press,, Princeton, NJ; Davidson and MacKinnon, ref. 43 above.

55 Gonzalo, J. and Granger, C. W. J. (1995) 'Estimation of Common Long-Memory Components in Cointegrated Systems', Journal of Business \& Economic Statistics, Vol. 1, No. 1, pp. 27-35.

56 One might explain greater explanatory power of past equity prices, especially for ABS-equity pairs with CMBS/RMBS, on the grounds of market liquidity. Issuers of CMBS/RMBS tend to be larger and tender more actively traded equity than issuers of whole business ABS, whose lack of operational scale makes them issue securitised debt only as a complementary source of external finance. Univariate descriptive statistics (not reported) of equity prices of issuers of whole business ABS also exhibit higher persistence of the sample period with longer autoregressive cycles than equity series of ABS-equity pairs associated with CMBS/RMBS issuers.

57 Also note that the equity of issuers of whole business ABS might be less liquid than the equity of CMBS issuers, which tend to be large banks, 
non-bank financial institutions and real estate agencies.

58 Note that the cross-sectional qualification of co-movement based on issuer domicile, ABS rating and maturity as selection criteria does not imply significant selective bias.

59 Although one cannot claim an equivalence relationship between $\mathrm{ABS}$ and equity under arbitrage-free conditions owing to missing fundamental information about the proximity of ABS to the change of issuer valuation, note that varying price responses between equity and ABS would allow traders in these markets to appropriate arbitrage gains from price differentials in the short run.

60 Although the same intuition applies, different economic significance is acknowledged, depending on the structural characteristics of ABS.

\section{APPENDIX 1: RELATIONSHIP BETWEEN BOND, ABS AND EQUITY PRICES}

In synthetic $\mathrm{CDO}$ and $\mathrm{ABS}$ transactions with on-balance-sheet reference assets, the intuition behind the empirical relation of securitised debt and equity claims can be assessed based on the valuation of balance sheet identities in the context of the capital structure-based OPT by Merton. ${ }^{17,60}$

According to Merton's structural model, a firm's outstanding liabilities constitute a bankruptcy level as a 'distance to default' threshold. Owners of corporate equity in leveraged firms have the option to default if their firm's asset value (reference asset) declines below the cumulative face value of outstanding debt (strike price) owed to bondholders at maturity. Hence, equity and debt are always positively correlated. Their correlation increases in higher default risk and leverage, which imply a higher probability that the asset value of the firm will drop below the default threshold. Bond and equity prices should also be cointegrated and share an equilibrium price relationship.

Merton's balance sheet approach assumes that the firm's debt consists of a zero-coupon bond with a notional value $F$ and maturity of $T$ periods. The firm's outstanding liabilities constitute a bankruptcy level as a 'distance to default', whose threshold value is density of the standard normal for a given probability of default if the firm's asset process is lognormal. This capital structure-based evaluation of contingent claims on firm performance implies that the firm defaults if its asset value is insufficient to meet the amount of debt owed to bondholders at maturity. By definition, the firm's bond price $B$ and equity price $E$ are always positively correlated and can be represented as $B / E=\left[\Phi\left(d_{1}\right)-d \Phi\left(d_{2}\right)\right]^{-1}$ where the firm leverage $d=\mathrm{Fe}^{-r T} / V$ is the ratio of the face value of outstanding debt $F$,

discounted by the risk-free rate $r$, and the asset value of the firm $V$, with $d_{1}=\left[\log (d)+1 / 2 \sigma^{2} \mathrm{~T}\right] / \sigma \sqrt{T}$ and $d_{2}=d_{1}-\sigma \sqrt{T}$ and $\Phi$ as the standard normal c.d.f. So prices of equity and bonds move in same direction. The correlation of bond and equity prices increases in the firm's leverage and approaches 0 whenever $B / E \rightarrow 0$. Moreover, the proximity of the firm's asset value to the default threshold, which is reflected in the default risk, contributes to a closer association of the valuation of debt and equity with the asset value of firms. Since low-rated firms have an asset value just enough to cover debt obligations, a small deterioration of asset value causes default, with negative price 
(co-)movement of debt holders and equity holders as residual claimant. Highly rated firms, in contrast, shed correlation between issued equity and debt claims as even larger deteriorations in asset value would not compromise their ability to repay existing debt. The positive relation between equity and debt also increases in the leverage ratio, which induces a higher probability that the asset value of the firm will drop below the default threshold of outstanding debt at the time of maturity. 


\section{APPENDIX 2: TABLES}

\section{Univariate descriptive statistics: sample composition, stationarity, autocorrelation and cointegration}

\section{Sample composition}

Table A1: Cross-sectional sample descriptives of $A B S$ and equity price series

$$
\text { ABS/equity sample composition (cross-sectional) }
$$

Total number of equity series (ie issuers)

Org. total number of ABS tranches (ABS transactions)

Selected number of ABS tranches (ABS transactions)

Rated by one/two/three rating agencies

Rated by Moody's/S\&P/Fitch

Jointly rated by

$$
\text { Moody's \& Fitch }
$$

S\&P \& Fitch

Moody's \& S\&P

Composite rating of $\mathrm{ABS}$ tranches

Mean

Median

Mode

ABS tranche size

Mean

Median

Remaining maturity of tranches (at sample start date)

Mean/median/mode

Remaining maturity of tranches (at sample end date)

Mean/median/mode

Seasoning of tranches (at sample end date)

Mean/median/mode
35

$81(48)$

$68(42)$

$11 / 26 / 30$

$41 / 44 / 64$

40

42

30

4.16 (AA-,Aa3)

3.00 (AA,Aa2)

1.00 (AAA,Aaa)

$\approx$ Brit. f283,058,168

$\approx$ Brit. £240,000,000

yr

$26.73 / 29.16 / 35.10 \mathrm{yr}$

$21.33 / 23.76 / 29.70 \mathrm{yr}$

$3.07 / 2.90 / 0.20$ 
Table A2: Pooled correlation measures of all matched ABS and equity pairs by crosssectional variation for two sub-samples of whole business $A B S$ and CMBS/RMBS as $A B S$ price series (without cointegration restriction).

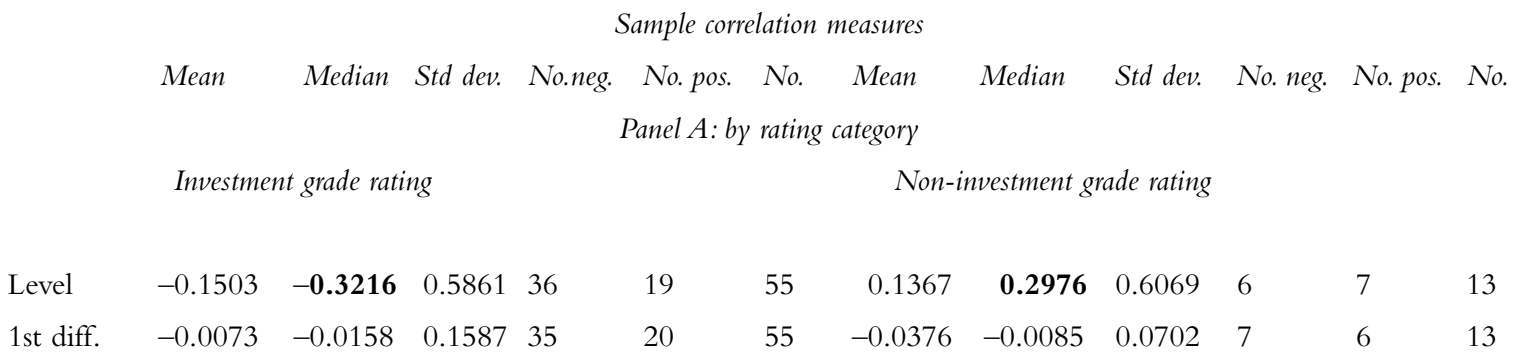

Panel B: by ABS type

Whole business

CMBS/RMBS/Other

\begin{tabular}{|c|c|c|c|c|c|c|c|c|c|c|}
\hline Level & 0.1603 & 0.3608 & $0.6171 \quad 13$ & 17 & 30 & -0.3180 & -0.4480 & 0.4829 & 26 & 9 \\
\hline 1st diff. & 0.0086 & -0.0088 & $0.1936 \quad 17$ & 13 & 30 & -0.0303 & -0.0199 & 0.0925 & 25 & 13 \\
\hline
\end{tabular}

Panel C: only whole business ABS

Investment grade rating

Non-investment grade rating

$\begin{array}{lrrrrrrrrrrrrr}\text { Level } & 0.1863 & \mathbf{0 . 4 1 9 6} & 0.6023 & 9 & 14 & 23 & 0.0750 & \mathbf{- 0 . 2 8 3 6} & 0.7067 & 4 & 3 & 7 \\ \text { 1st diff. } & 0.0239 & -0.0050 & 0.2155 & 13 & 10 & 23 & -0.0416 & -0.0476 & 0.0837 & 4 & 3 & 7\end{array}$

Panel D: only CMBS/RMBS/other ABS

Investment grade rating

Non-investment grade rating

$\begin{array}{lrrrrrrrrrrrr}\text { Level } & -0.3923 & -\mathbf{0 . 5 1 5 8} & 0.4432 & 27 & 5 & 32 & 0.0778 & \mathbf{0 . 3 1 7 5} & 0.5336 & 2 & 4 & 6 \\ \text { 1st diff. } & -0.0298 & -0.0255 & 0.0983 & 22 & 10 & 32 & -0.0329 & -0.0024 & 0.0580 & 3 & 3 & 6\end{array}$


Table A3: Pooled correlation measures of all matched and cointegrated ABS and equity pairs by cross-sectional variation for two sub-samples of whole business $A B S$ and CMBS/RMBS as $A B S$ price series

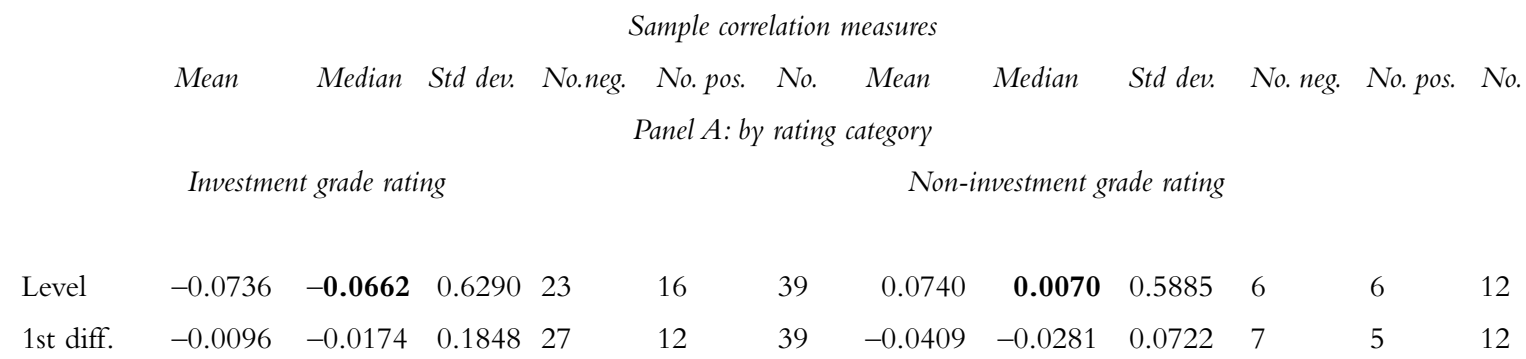

Panel B: by ABS type

Whole business

CMBS/RMBS/Other

\begin{tabular}{|c|c|c|c|c|c|c|c|c|c|c|c|}
\hline Level & 0.2750 & 0.5626 & 0.5890 & 8 & 13 & 21 & -0.2827 & 66 & 0.5296 & 21 & 9 \\
\hline 1st diff. & 0.0054 & -0.0174 & 0.2319 & 15 & 6 & 21 & -0.0326 & -0.0199 & 0.0967 & 19 & 11 \\
\hline
\end{tabular}

Panel C: only whole business ABS

Investment grade rating

Non-investment grade rating

$\begin{array}{lrrrrrrrrrrrr}\text { Level } & 0.4051 & \mathbf{0 . 5 7 2 4} & 0.5150 & 4 & 11 & 15 & -0.0504 & \mathbf{- 0 . 3 5 7 7} & 0.6836 & 4 & 2 & 6 \\ \text { 1st diff. } & 0.0271 & -0.0158 & 0.2687 & 11 & 4 & 15 & -0.0490 & -0.0682 & 0.0892 & 4 & 2 & 6\end{array}$

Panel D: only CMBS/RMBS/other ABS

Investment grade rating

Non-investment grade rating

$\begin{array}{lrrrrrrrrrrrrr}\text { Level } & -0.3729 & -\mathbf{0 . 5 1 5 8} & 0.4993 & 19 & 5 & 24 & 0.0583 & \mathbf{0 . 1 4 8 8} & 0.4524 & 19 & 5 & 24 \\ \text { 1st diff. } & -0.0325 & -0.0199 & 0.1051 & 16 & 8 & 24 & -0.0247 & 0.0000 & 0.0513 & 16 & 8 & 24\end{array}$


Table A4: Cointegration test of ABS and equity level data: The Johansen test identifies the cointegration relationship (ie the existence of cointegration vectors ('CE')) of all matched (68) ABS-equity pairs on a level basis. The cross-sectional variation of cointegration relationships is also tested for two sub-samples of whole business $A B S$ and CMBS/RMBS/other ABS as ABS price series. For each panel, the cases when the null hypothesis of no cointegrating vector cannot (N.S.) or can be rejected at the $5 \%(1 \%)$ significance level across the entire sample are counted. The subsequent columns present median and mean eigenvalues as well as the trace statistic (with critical value at the 5\% (**) and the $1 \%\left(^{* * *}\right)$ significance level) of all matched $A B S$-equity pairs

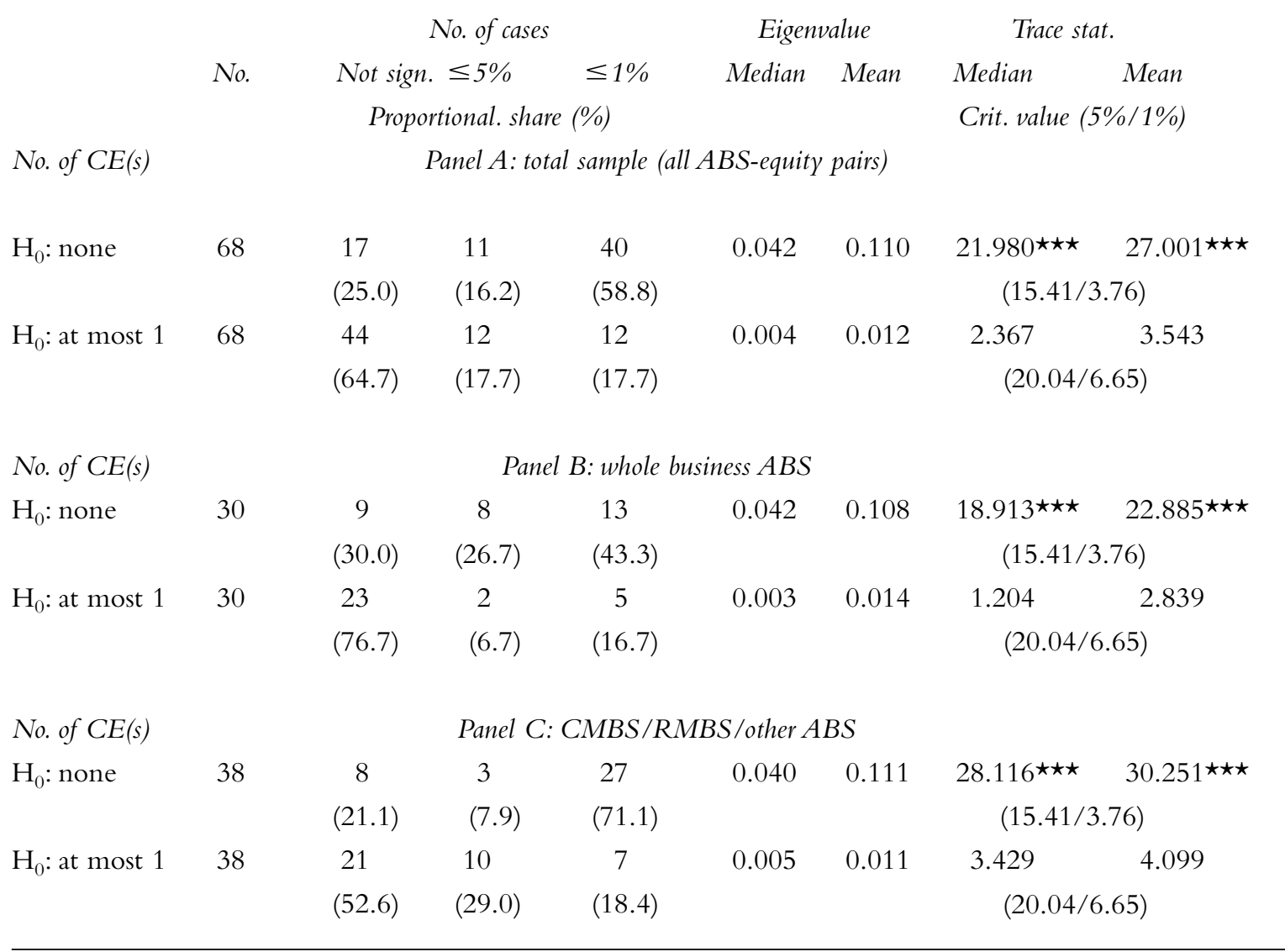




\section{Estimation results of short-term dynamics: Granger causality test (linear)}

Table A5: Granger causality test of ABS-equity pairs and sub-samples at first differences without cointegration restriction (Panel $A$ ) and with cointegration restriction (Panel B)

Panel A: All series without cointegration restriction Panel B: Only cointegrated series

Total sample

\begin{tabular}{lcccccccccccc} 
& \multicolumn{3}{c}{ Sign. level } & \multicolumn{1}{c}{ Sign. level } \\
Direction of causality & $\leq 10 \%$ & $\leq 5 \%$ & $\leq 1 \%$ & No. & $\%$ expl. & $\leq 10 \%$ & $\leq 5 \%$ & $\leq 1 \%$ & No. & $\%$ expl. \\
& & & & & & & & & & \\
& 10 & 9 & 2 & 68 & 14.71 & 8 & 7 & 2 & 51 & 15.69 \\
{$\left[\Delta B_{t}\right] \mathrm{H}_{1}$ : Equity expl. ABS } & 10 & 15 & 9 & 68 & 25.00 & 14 & 12 & 8 & 51 & 27.45 \\
{$\left[\Delta S_{t}\right] \mathrm{H}_{1}$ : ABS expl. equity } & 17 & 15 & 24 & 11 & 68 & 39.71 & 22 & 19 & 10 & 51 & 43.14 \\
Total & 27 & 24 &
\end{tabular}

Whole business ABS

Sign. level Sign. level

Direction of causality $\quad \leq 10 \% \quad \leq 5 \% \quad \leq 1 \% \quad$ No. $\%$ expl. $\leq 10 \% \leq 5 \% \leq 1 \% \quad$ No. $\%$ expl.

$\begin{array}{llllrrrrrrr}{\left[\Delta B_{t}\right] \mathrm{H}_{1} \text { : Equity expl. ABS }} & 7 & 6 & 2 & 30 & 23.33 & 6 & 5 & 2 & 21 & 28.57 \\ {\left[\Delta S_{t}\right] \mathrm{H}_{1} \text { : ABS expl. equity }} & 2 & 1 & - & 30 & 6.67 & 2 & 1 & - & 21 & 9.52 \\ \text { Total } & 9 & 7 & 2 & 30 & 30.00 & 8 & 6 & 2 & 21 & 38.09 \\ & & & 46.67 & & & & & & \end{array}$

CMBS/RMBS/other ABS

Sign. level Sign. level

Direction of causality $\quad \leq 10 \% \leq 5 \% \leq 1 \%$ No. $\%$ expl. $\leq 10 \% \leq 5 \% \leq 1 \% \quad$ No. $\%$ expl.

$\left[\begin{array}{lllllllllll}\left.\Delta B_{t}\right] \mathrm{H}_{1} \text { : Equity expl. ABS } & 3 & 3 & - & 38 & 7.89 & 2 & 2 & - & 30 & 6.67\end{array}\right.$

$\left[\begin{array}{lllllllllll}\left.\Delta S_{t}\right] \mathrm{H}_{1} \text { : ABS expl. equity } & 15 & 14 & 9 & 38 & 39.47 & 12 & 11 & 8 & 30 & 40.00\end{array}\right.$

$\begin{array}{llllllllll}\text { Total } & 18 & 17 & 9 & 38 & 47.36 & 14 & 13 & 8 & 30\end{array}$




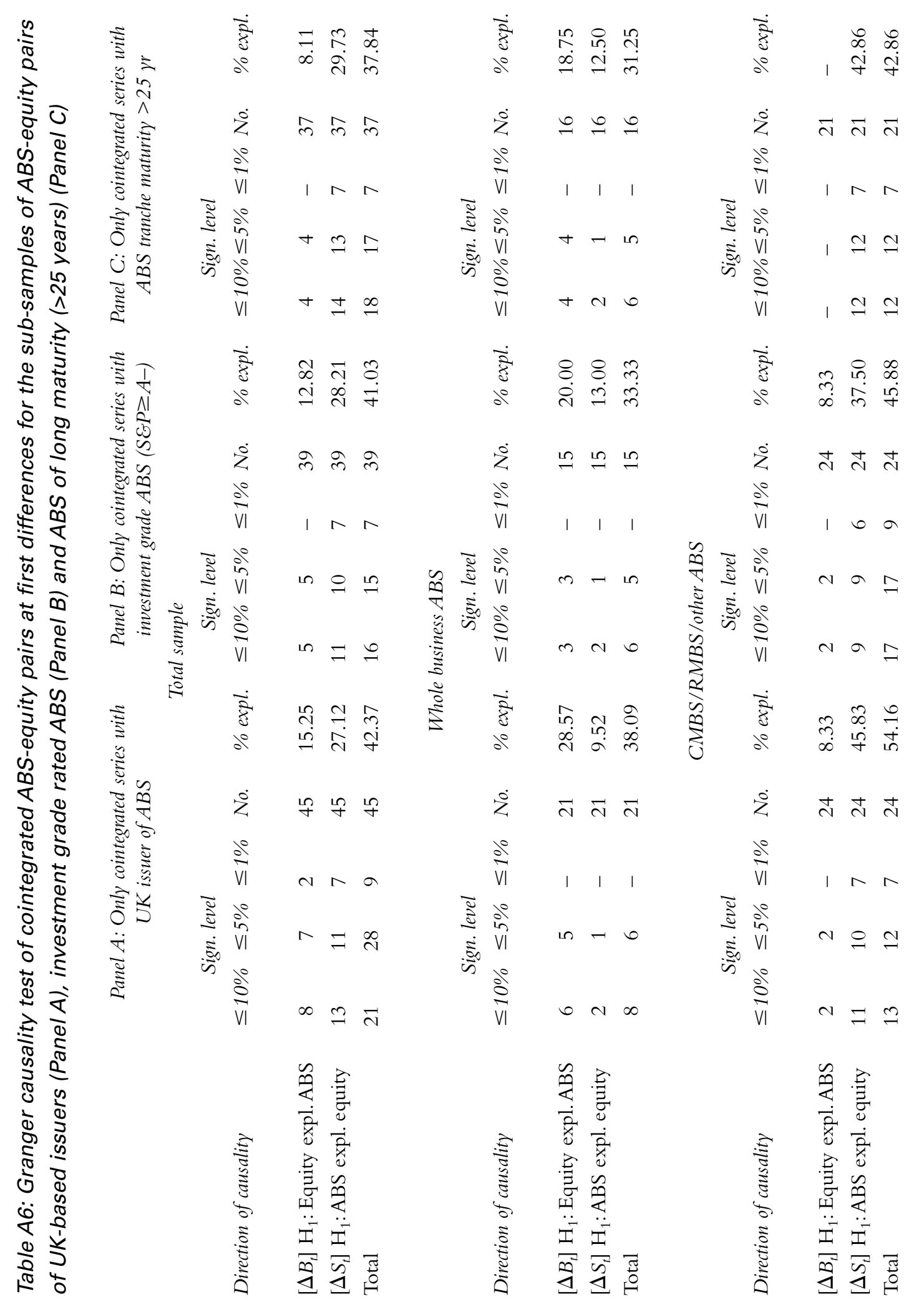




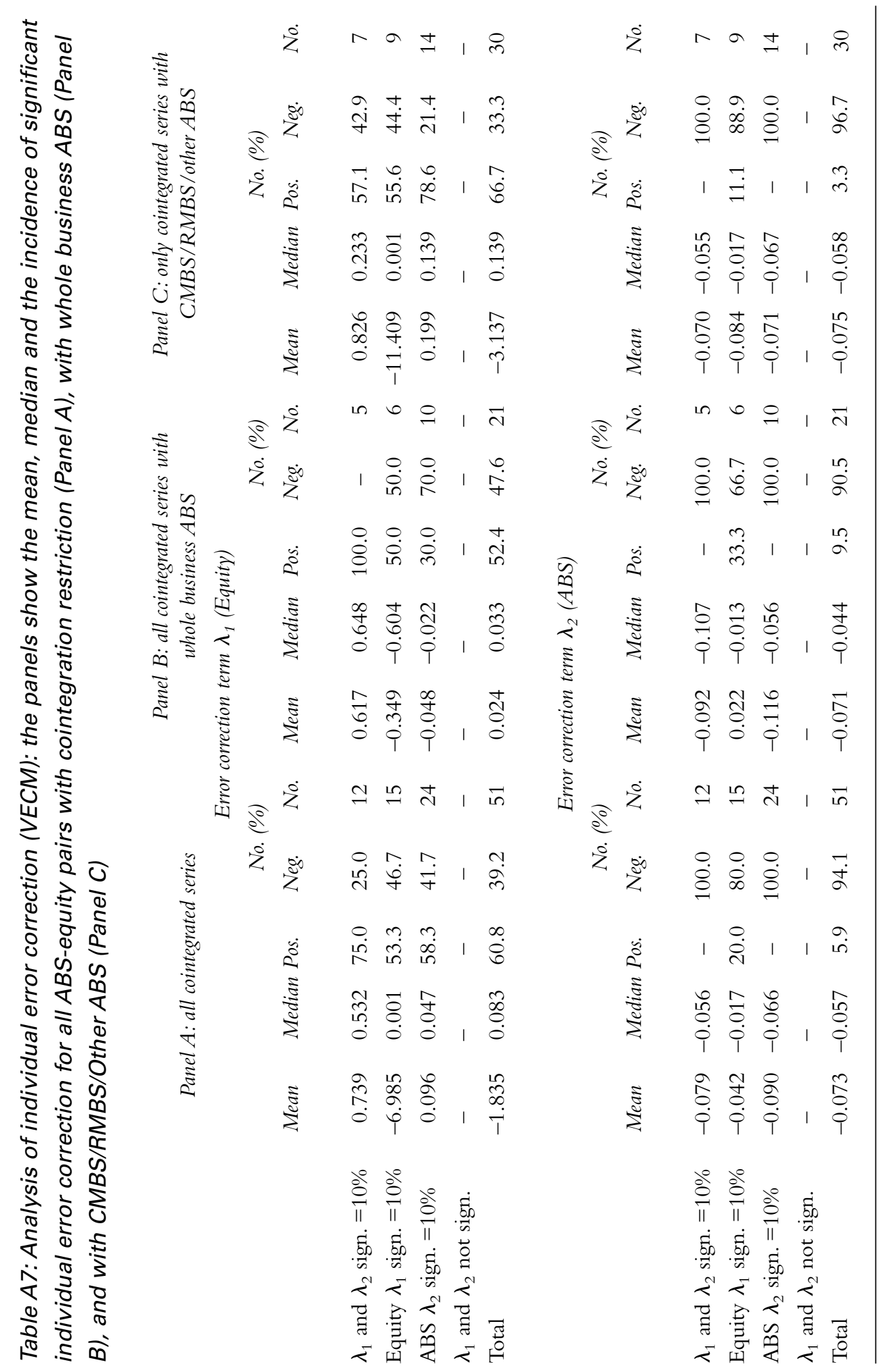




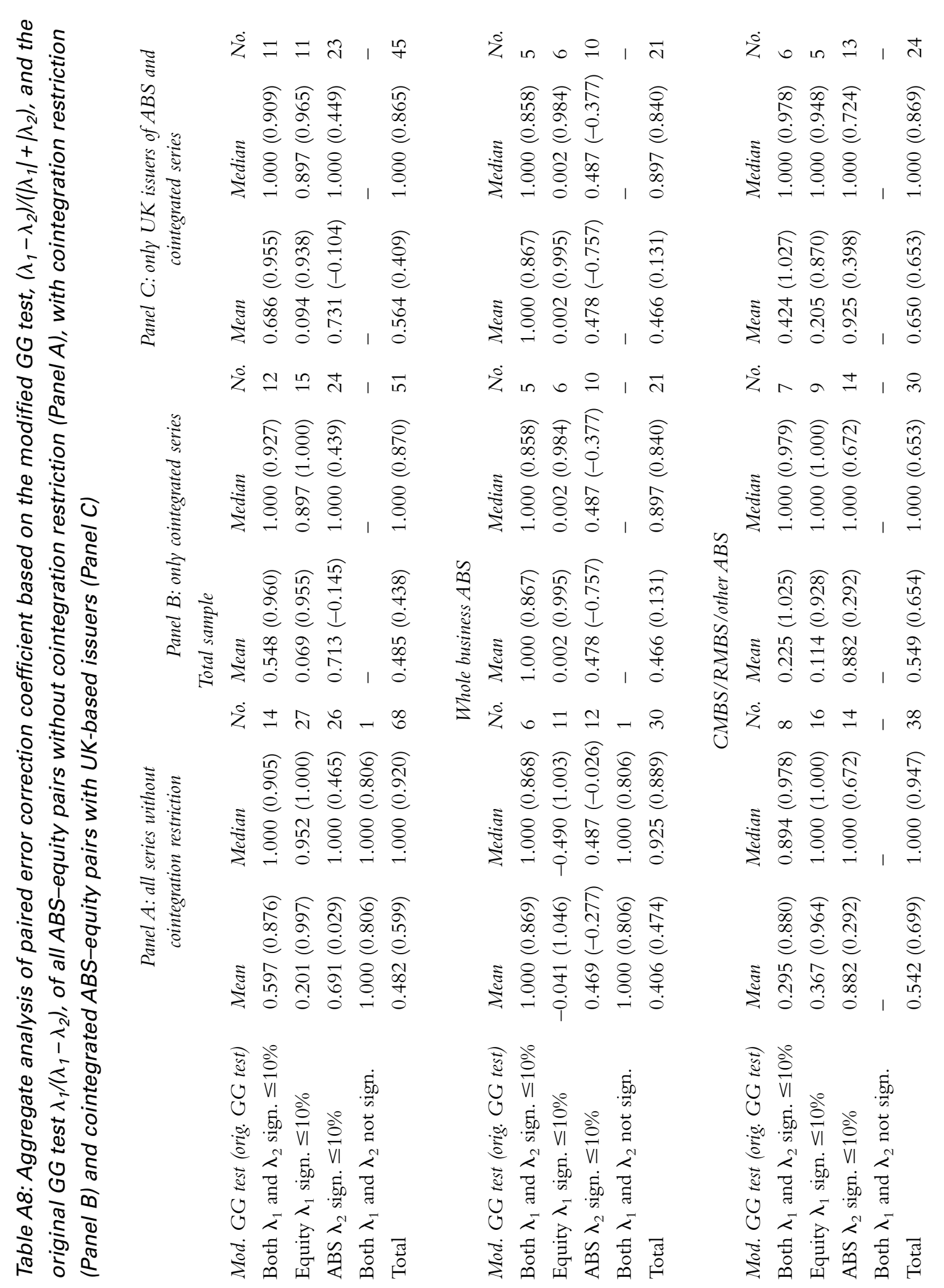




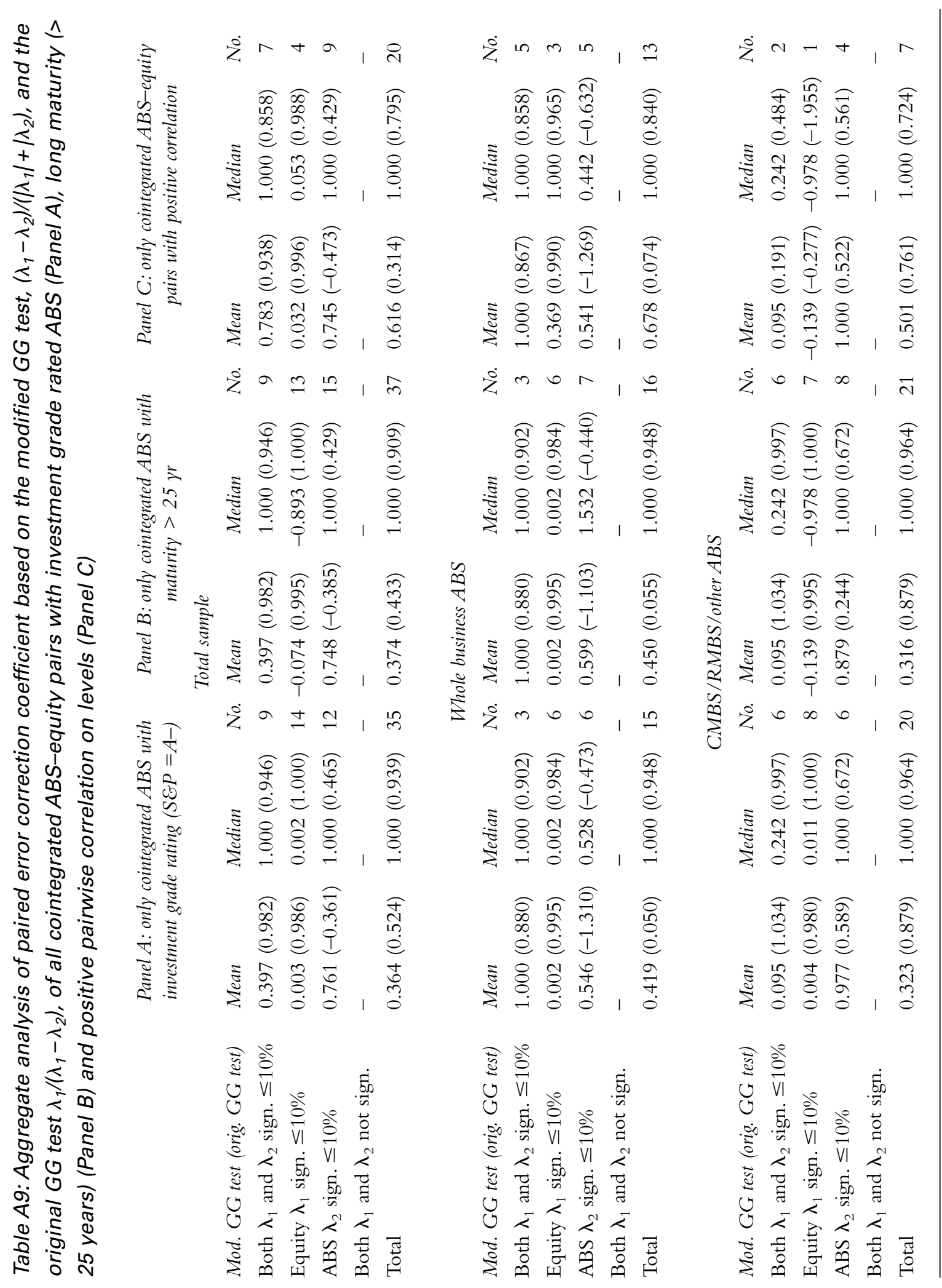

